ANL-7554

$D W R-1216$

ANL-7554

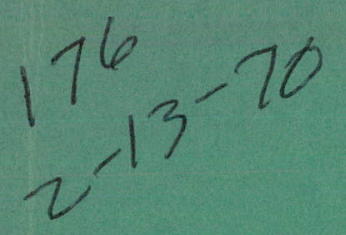

Argonne Mational Laboratom

\title{
THE EDDY-CURRENT FLOWMETER:
}

An Analysis Giving Performance Characteristics and Preferred Operating Conditions by
David E. Wiegand 


\section{DISCLAIMER}

This report was prepared as an account of work sponsored by an agency of the United States Government. Neither the United States Government nor any agency Thereof, nor any of their employees, makes any warranty, express or implied, or assumes any legal liability or responsibility for the accuracy, completeness, or usefulness of any information, apparatus, product, or process disclosed, or represents that its use would not infringe privately owned rights. Reference herein to any specific commercial product, process, or service by trade name, trademark, manufacturer, or otherwise does not necessarily constitute or imply its endorsement, recommendation, or favoring by the United States Government or any agency thereof. The views and opinions of authors expressed herein do not necessarily state or reflect those of the United States Government or any agency thereof. 


\section{DISCLAIMER}

Portions of this document may be illegible in electronic image products. Images are produced from the best available original document. 
The facilities of Argonne National Laboratory are owned by the United States Government. Under the terms of a contract (W-31-109-Eng-38) between the U. S. Atomic Energy Commission, Argonne Universities Association and The University of Chicago, the University employs the staff and operates the Laboratory in accordance with policies and programs formulated, approved and reviewed by the Association.

\section{MEMBERS OF ARGONNE UNIVERSITIES ASSOCIATION}

The University of Arizona Carnegie-Mellon University Case Western Reserve University 'l'he University of Chicagu University of Lincinnati Illinuis Institute of Technology University of Illinois Indiana University Iowa State University The University of Iowa
Kansas State University The University of Kansas Loyola University Marquette University IVichigan Stato University The University of Michigan University of Minnesuta University of Missouri Northwestern University University of Notre Dame
The Ohio State University Ohio University

The Pennsylvania State University Purdue University

Saint Louis University

Southern Illinois University

University of Texas

Washington University

Wayne State University

The University of Wisconsin

\section{LEGAL NOTICE}

This report was prepared as an account of Government sponsored work. Neither the United States, nor the Commission, nor any person acting on behalf of the Curmunissiun:

A. Makes any warranty or representation, expressed or implied, with respect to the accuracy, completeness, or usefulness of the information contained in this report, or that the use of any information, apparatus, method, or process disclosed in this report may not infringe privately owned rights; or

B. Assumes any liabilities with respect to the use of, or for damages resulting from the use of any information, apparatus, method, or process disclosed in this report.

As used in the above, "person acting on behalf of the Commission" includes any employee or contractor of the Commission, or employee of such contractor, to the extent that such employee or contractor of the Commission, or employee of such contractor prepares, disseminates, or provides access to, any information pursuant to his employment or contract with the Commission, or his employment with such contractor.

Printed in the United States of America Available from

Clearinghouse for Federal Scientific and Technical Information

National Bureau of Standards, U. S. Department of Commerce

Springfield, Virginia 22151

Price: Printed Copy $\$ 3.00$; Microfiche $\$ 0.65$ 
ANL- 7554

Engineering and Equipment

\section{ARGONNE NATIONAL LABORATORY \\ 9700 South Cass Avenue \\ Argonne, Illinois 60439}

THE EDDY-CURRENT FLOWMETER:

An Analysis Giving Performance Characteristics and Preferred Operating Conditions

by

David E. Wiegand

Reactor Engineering Division

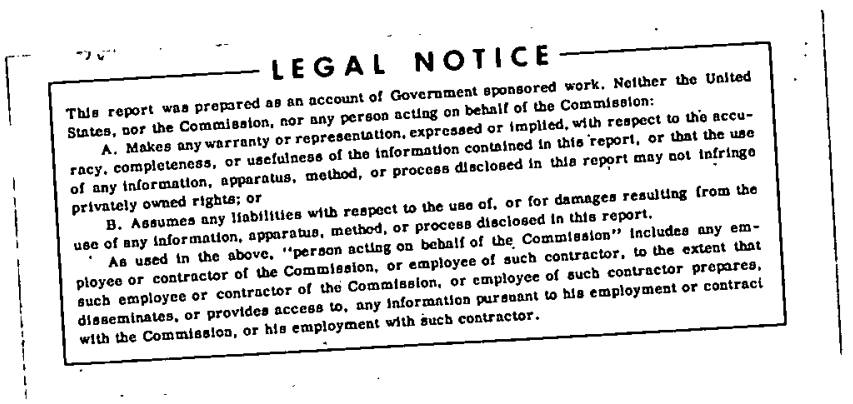

August 1969 


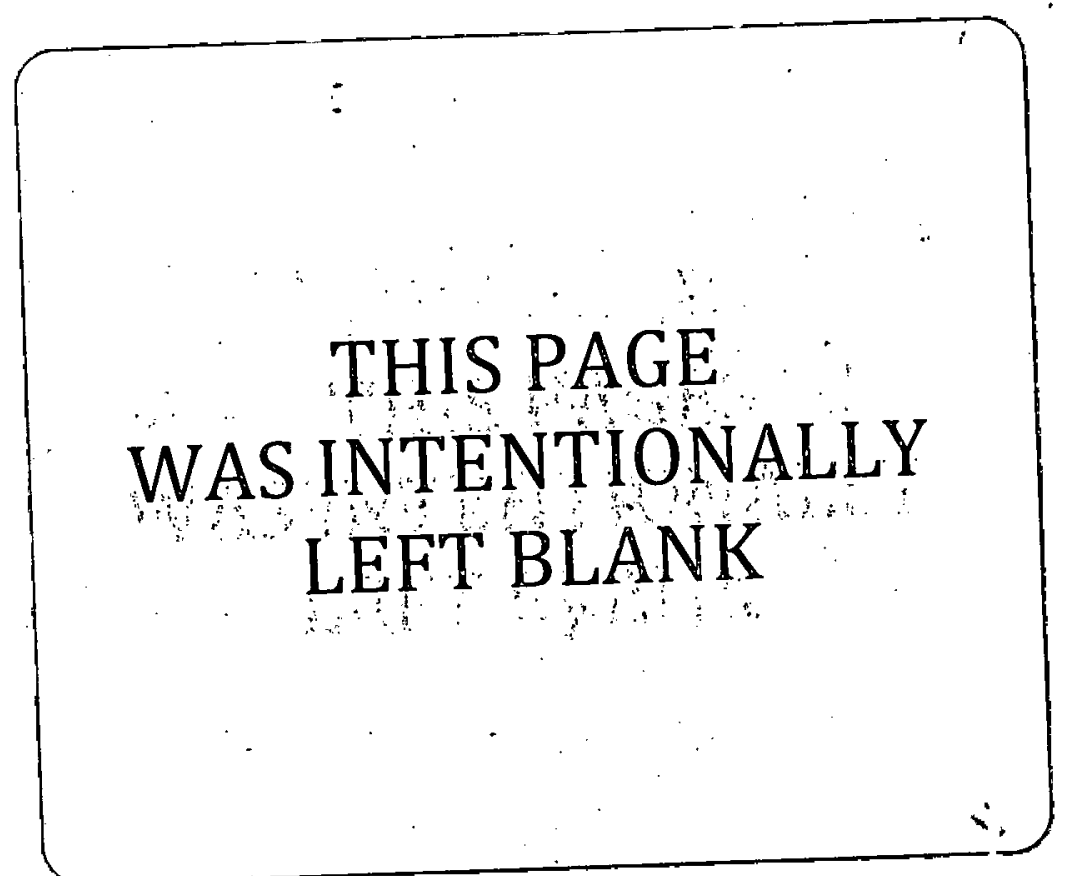


TABLE OF CONTENTS

$\underline{\text { Page }}$

NOMENCLATURE ............................ 6

ABSTRACT .................... 7

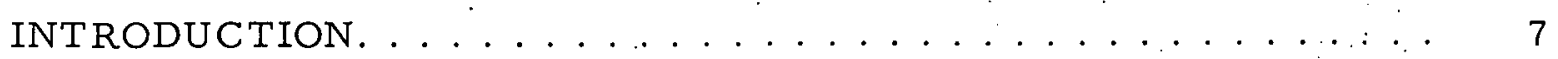

ELECTRODYNAMIC RECIPROCITY $\ldots \ldots \ldots \ldots \ldots . \ldots . \ldots$

SIGNAL-PROFILE FUNCTION $\ldots \ldots \ldots \ldots \ldots$ io

VELOCITY PROFILES . ....................... 19

VARIATION OF SIGNAL WITH REYNOLDS NUMBER AND

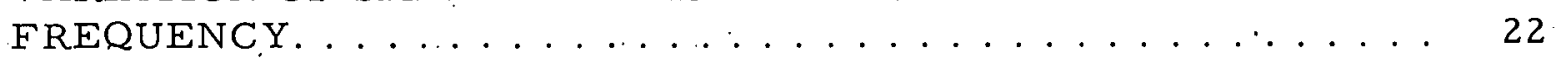

TEMPERATURE ERRORS .................. 26

EFFECT OF PIPE WALL ................. 28

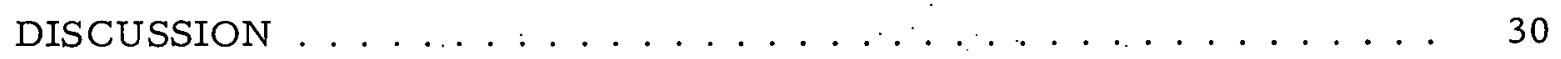

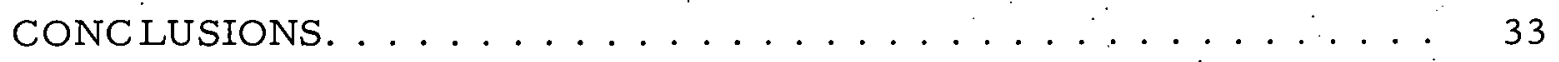

APPEND:

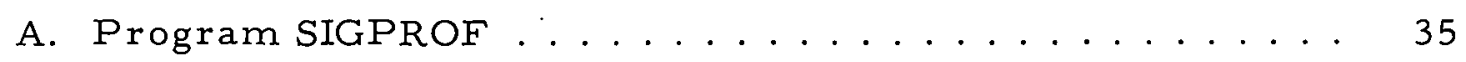

B. Program FLOMGEN $\ldots \ldots \ldots \ldots \ldots \ldots \ldots \ldots \ldots$

C. Program FLOMTEMP . . . . . . . . . . . . . . . . 54:

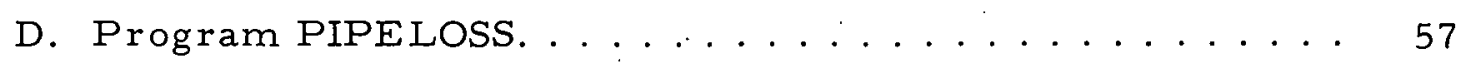

E. Subroutines . . . . . . . . . . . . . . 59

ACKNOWLEDGMENT $\ldots \ldots \ldots \ldots . \ldots \ldots \ldots$

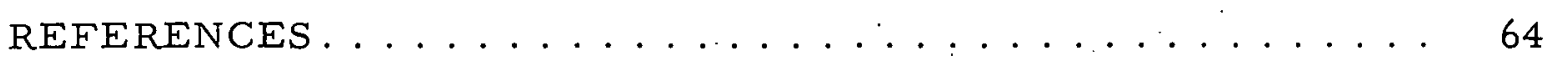




\section{LIST OF· FIGURES}

No.

Title

$\underline{\text { Page }}$

1. Forces between Coils ................... 8

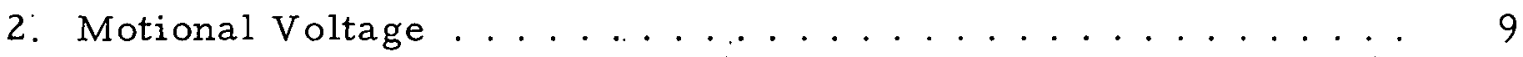

3. Eddy-current Flowmeter with Four Primary-Secondary

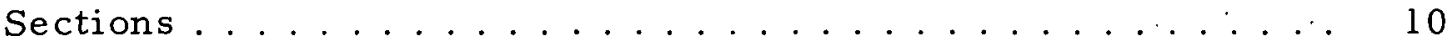

4. In-phase Component of Signal-profile Function . . . . . . . 18

5. Quadrature Component of Signal-profile Function. . . . . . 18

6. Velocity Profiles, Radius Base............... 22

7. Velocity Profiles, Area Base ................. 22

8. In-phase Component of Normalized Signal. . . . . . . . . . 24

9. Quadrature Component of Normalized Signal . . . . . . . . 24

10. Magnitude of Normalized Signal . . . . . . . . . . . . 24

11. Phase Angle of Signal . . . . . . . . . . . . . . . . 24

12. Temperature Variation of In-phase Component . . . . . . . 27

13. Temperature Variation of Quadrature Component. . . . . . . 27

14. Temperature Variation of Signal Magnitude. . . . . . . . . 27

15. Temperature Variation of Signal Phase ........... 27

\section{LIST OF TABLES}

No:

Title

$\underline{\text { Page }}$

I. Velocity-profile Variables................... 22

II. Optimum Operating Frequencies for Sodium at $400^{\circ} \mathrm{C} \ldots \ldots 25$

III. Uncompensated Temperature Errors . . . . . . . . . . . . 27 


\section{THIS PAGE \\ WAS INTENTIONALLY \\ LEFT BLANK}


a Dimensionless variable, proportional to an area (Eq. 62).

A - Area of a circle of radius $r$ (Eq. 521 .

A, B Constants in a velocity-profile relation (Eq. 65).

$A_{C} \quad$ Area of the flow channel (Eq. 54).

be Complex combination of ber and bei (Eq. 35).

ber, bei,

ker, kei Kelvin functions of zero order (Eq. 25).

$\mathrm{Br}_{\mathrm{r}}$

Average radial component of magnetic induction at radius $r$, inside a secondary coil section (Eq. 42 ).

$\mathrm{C}_{1}, \mathrm{C}_{2}$ Arbitrary constants in the solution of the Bessel equation (Eq. 25 ).

$d_{1}, d_{2}$,

$d_{3}, \ldots$

Primary (driver) coil sections (Fig. 3).

dber, dbei Derivatives of the Kelvin functions (Eq. 82).

DC Diameter of the flow channel (Eq. 45).

i Frequency of the primary current (Eq. 52).

F Force (Eq. 1).

$F_{\text {Sp }} \quad$ Signal-profile function (EQ. 57).

FUNCR, Real and imaginary components of a dimensionless variable used in

FUNCl calculating pipe-wall effects (Egs. 92 and 93 ).

91, 92,

$93, \ldots$

G

G

$G_{p}$

H

$\mathrm{HO}_{0}$

$H_{d}$

$H_{0}$

$\mathrm{H}_{0 \mathrm{~d}}$

$\mathrm{H}_{0 \mathrm{~g}} \quad$ Field at the axis due to the secondary coil current (Eq. 47).

Secondary (generatori coil sections (Fig. 3).

Circumferential conductance (Eq. 12).

Gain factor for the flowmeter (Eq. 97)

Circumferential conductance of a length $\ell$ of pipe (Eq. 85 ).

Axial component of field intensity (Eq. 15 ).

Axial component of field intensity at the axis of the flow channel (Eq. 27).

Axial component of field intensity at the end of a primary coil section at radius $r$ (Eq. 36 ).

Axial component of field intensity at the axis of a primary coil section (Eq. 38).

$\mathrm{H}_{5 \mathrm{~d}} \quad$ Axial component of field intensity at the outside fluid surface at a primary-secondary coil interface (Eq. 44$)$

$\mathrm{H}_{S} \quad$ Axial component of field intensity inside the pipe (Eq. 88 ).

$\mathrm{H}_{\mathrm{p}} \quad$ Axial component of field intensity outside the pipe (Eq. 90).

$\mathrm{H}_{\mathrm{sg}} \quad$ Axial component of field intensity at the outside fluid surface due to a current in the secondary coils (Eq. 99).

Circumferential current in the pipe (Eq. 89).

$\mathrm{i}_{1}$

$\mathrm{i}_{2}$

I

Id

$I_{g}$

Ilm

j

Kind

King

Current in the primary winding of a mutual inductor (Eq. 1).

Current in the secondary winding of a mutual inductor (Eq. 1).

Circumferential current in the fluid inside a secondary coil (Eq. 47).

Current in the primary winding of a flowmeter (p. 10).

Current in the secondary winding of a flowmeter (p. 10).

Maximum value of $i_{1}(E q .3)$.

Square root of -1 (Eq. 13).

Dimensionless constant, depending on the geometry of the primary coil system (Eq. 45).

Dimensionless constant, depending on the geometry of the secondary coil system (Eq. 48).
$\mathrm{K}_{\mathrm{n}}$

$\ell$

$\ell$

$\ell_{g}$

m

$M$

$n$

$N_{d}$

Ndg

$\mathrm{Ng}_{\mathrm{g}}$

9

$r$

$r_{1}$

$\mathrm{R}$

Re

RE400

$s$

$\$ 400$

$t$

t

u

u

$\mathrm{u}$

$u_{a}$

$u_{m}$

V

$v_{2}$

$\mathrm{V}_{2 \mathrm{u}}$

$v_{n}$

VR, VI

VS, VA

$x$

$x$ i

$x$

$x_{1}$

$x_{5}$

$a_{1}$

$\mu$

$\mu$

$p$

Pf
Normalization factor for the signal voltage (Eq. 59).

Length of a coil (Eq. 12).

Length of a pipe (Eq. 85).

Length of a secondary (generator) coil (Eq. 42).

Exponent in the velocity-profile equation applied to areas (Eq. 78).

Mutual inductance (Eq. 1$)$.

Exponent in the velocity-profile equation applied to radii (Eq. 69).

Number of turns in a primary coil section (Eq. 45).

Number of primary-secondary coil sections (Eq. 56).

Number of turns in a secondary coil section (Eq. 48).

Volume rate of the fluid (Eq. 96).

Radial distance in the fluid (Eq. 12).

Value of $r$ at limit of integration (Eq. 36).

Channel radius (Eq. 80 ).

Reynolds. number (Eq. 65).

Reynolds number for a fluid temperature of $400^{\circ} \mathrm{C}$ (p. 26).

Value of a corresponding to the channel cross-section area (Eq. 61).

Selected value of $s$ for a fluid temperature of $400^{\circ} \mathrm{C}$ (p. 26).

Time (Eq. 3).

Thickness of the pipe (Eq. 85).

Velocity of a mutual-inductor coil (Eq. 7).

Velocity of a hollow-cylindrical element of fluid (Eq. 56).

Average fluid velocity (Eq. 58 ).

Maximum fluid velocity (Eq. 65).

Secondary voltage developed by the motion of the fluid (Eq. 56).

Secondary voltage (Eq. 5).

Motional component of voltage (Eq. 8).

Normalized signal voltage (Eq. 95).

Real and imaginary components of signal voltage (p. 23).

Magnitude and phase angle of signal voltage (p. 23 ).

Distance between the coils of a mutual inductor (Eq. 1 ).

Dimensionless variable in the Bessel equation (proportional to a radius) (Eq. 22).

The value of the dimensionless variable corresponding to radius $r_{1}$ (Eq. 38).

The value of the dimensionless variable corresponding to the radius of the flow channel (Eq. 46).

Time-displacement angle (Eq. 3).

Permeability of the fluid (Eq. 18).

Resistivity of the fluid (Eq. 12).

Resistivity of the fluid (same as $\rho$, but used to distinguish it from $\rho_{p}$ )

(Eq. 87).

Resistivity of the pipe (Eq. 85).

Magnetic flux (Eq. 14).

Flux within radius, $r_{1}$, at the end of a primary coil (Eq. 36).

$2 \pi$ times the frequency of the primary current

NOTE: Numbers in parentheses indicate where symbols are first used. 
THE EDDY-CURRENT FLOWMETER:

An Analysis Giving Performance Characteristics and Prefer red Operating Conditions

by

David E. Wiegand

\begin{abstract}
In the eddy-current flowmeter, motion of a fluid is measured through inductive coupling to exciting and sensing windings. An optimum excitation frequency, depending on the channel size and the fluid properties, yields maximum sensitivity. Operation in the region of the optimum frequency minimizes temperature errors and reduces velocityprofile effects.
\end{abstract}

\title{
INTRODUCTION
}

The eddy-current flowmeter is an ac-operated device in which eddy currents are induced in the (conducting) fluid by coupling to a primary coil system. Signal voltages are generated in a normally balanced secondary coil system through the distortion in the eddy-current pattern caused by the motion of the fluid.

A device using this principle was patented by Lehde and Lang. ${ }^{1}$ An encapsulated coil system immersed in the flow stream is described in the patent. This configuration was used in the British Prototype Fast Reactor ${ }^{2}$ as a flow-failure monitor. Calibration difficulties were experienced that did not rule out its use as a flow-failure monitor, however.

Shercliffe ${ }^{3}$ described the eddy-current flowmeter briefly and suggested an alternate construction with solenoidal coils wound around the

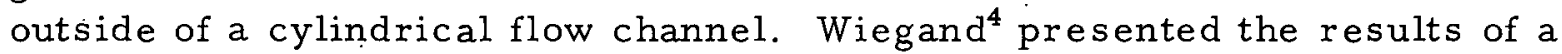
preliminary analysis of the external-coil configuration. This report presents, in complete form, a refined version of the earlier report.

Results of an experimental program on the eddy-current flowmeter have been presented by Wiegand and Michels. ${ }^{5}$

Flowmeter types in a high-temperature application were compared by Popper, Wiegand, and Glass. ${ }^{6}$ 


\section{ELECTRODYNAMIC RECIPROCITY}

The solution of many problems involving systems having relations between mechanical variables (velocity and force) and electromagnetic variables (voltage, current, magnetic induction, and magnetizing force) are simplified by use of the electrodynamic-reciprocity principle. This principle applies to systems having between two terminals a component of induced voltage that is proportional to the velocity of some member, and a force on the same member that is proportional to the cur rent into and out of the terminals. With a consistent set of units, the ratio of voltage to velocity is equal to the ratio of force to current.

Electrodynamic reciprocity applies to a large number of fixedfield devices, such as dc motors and generators, electrodynamic speakers, and microphones. The principle does not apply directly to square-law force devices, such as lifting magnets and nonpolarized relays, which, in the absence of a coil current, have no terminal voltage associated with a velocity.

The principle applies to ac devices having the required linear relations between selected components of current, voltage, force, and velocity. Consider, for example, the variable mutual inductor of Fig. 1 in which currents in the coils cause a force between them.
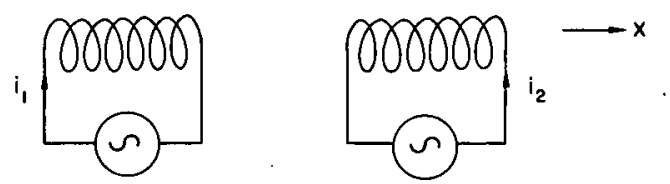

The force is related to the currents by

Fig. 1. Forces between Coils

$$
F=i_{1} i_{2} \frac{d M}{d x}
$$

where $F, i_{1}$, and $i_{2}$ are, in general, time-varying quantities, or

$$
\frac{F}{i_{2}}=i_{1} \frac{d M}{d x}
$$

Let $i_{1}$ have a sinusoidal variation,

$$
i_{1}=I_{1 m}\left(\sin \omega t+\alpha_{1}\right) \text {. }
$$

Then

$$
\frac{F}{i_{2}}=\frac{d M}{d x} I_{1 m} \sin \left(\omega t+\alpha_{1}\right)
$$

Now, replace the current source on the right-hand coil by a voltage indicator, as in Fig. 2. 


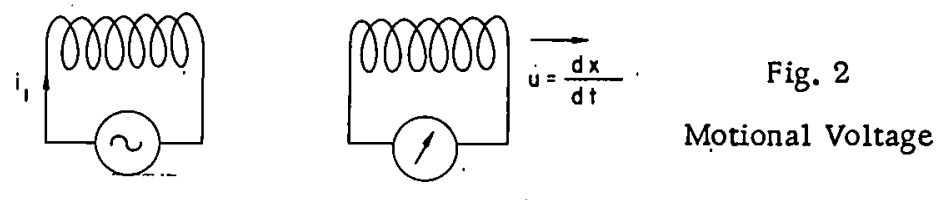

If the coil is moved in the $\mathrm{x}$ direction with a velocity $\mathrm{u}$, the induced voltage is given by

$$
\begin{aligned}
V_{2} & =M \frac{d i_{1}}{d t}+i_{1} \frac{d M}{d t} \\
& =M \frac{d i_{1}}{d t}+i_{1} \frac{d M}{d x} \frac{d x}{d t} \\
& =M \frac{d i_{1}}{d t}+u i_{1} \frac{d M}{d x}
\end{aligned}
$$

The component of voltage due to the motion is the right-hand term in Eq. 7 . Also,

$$
\frac{V_{2 u}}{u}=i_{1} \frac{d M}{d x}
$$

With the same sinusoidal variation on $i$ as in the previous case, and with a constant or slowly varying velocity $u$,

$$
\frac{V_{2 u}}{u}=\frac{d M}{d x} I_{1 m} \sin \left(\omega t+\alpha_{1}\right)
$$

By comparison with Eq. 4,

$$
\frac{V_{2 u}}{u}=\frac{F}{i_{2}} \text {. }
$$

In converting to the complex form for the ac quantities, we should write Eq. 10 as

$$
\frac{V_{2 u}}{u}=\left[\frac{F}{i_{2}}\right],
$$

where the brackets indicate that, while the quotient is a complex number, it is not the quotient of two complex numbers. F consists of a doublefrequency component superimposed on a constant value, and thus cannot be represented by a complex number. However, from Eq. 4 the quotient is a simple sinusoid at fundamental frequency and its complex notation is, therefore, legitimate. 
Analyzing the eddy-current flowmeter on the basis of motor action and then applying the reciprocity principle lend a degree of insight into the analysis not possible were the voltage calculated directly.

\section{SIGNAL-PROFILE FUNCTION}

In the eddy-current flowmeter, signal voltages are generated through the interaction of the axial fluid velocity with the radial component of the magnetic induction of the primary coil system. Radial fluxes are created more effectively by a group of short primary coil sections with suitable polarity reversals than by a single long coil. An example of this configuration is shown in Fig. 3, which is a section view of a flowmeter with four primary (driver) and four secondary (generator) coil sections wound around the flow channel. The central coil sections are wound in unit pairs (for example, $d_{2}$ and $d_{3}$ are wound as a single coil); division into sections as shown simplifies the analysis in that the signal voltage per primary-secondary section can be calculated.

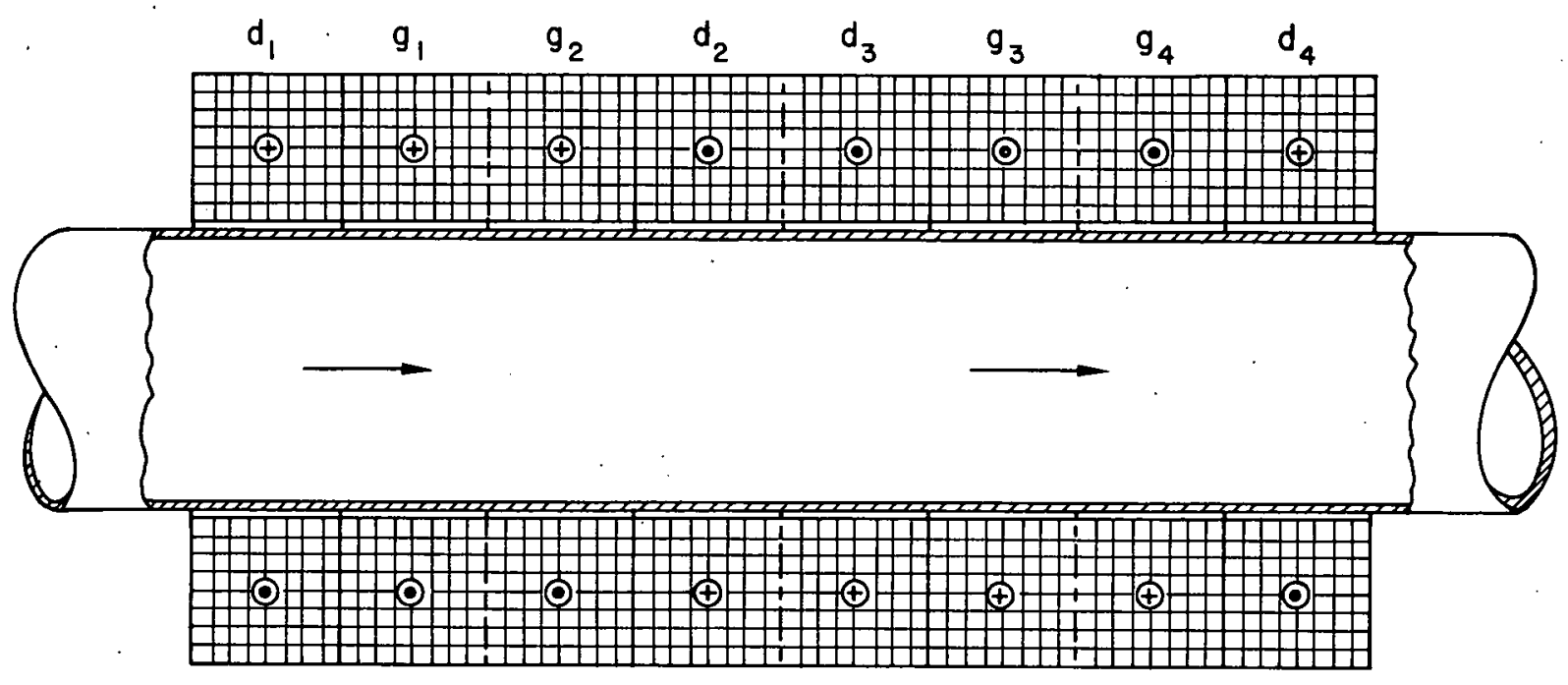

Fig. 3. Eddy-current Flowmeter with Four Primary-Secondary Sections

The system will be analyzed on the basis of the force that results on the fluid when ac currents $I_{g}$ and $I_{d}$ are made to flow in the secondary and primary coils, respectively. Application of the reciprocity principle will than give the secondary voltage that results from the fluid motion.

Although the coil sections of the proportions shown in Fig. 3 can hardly be considered "long," cylindrical geometry will be assumed in the calculation of the field-strength variation inside the coils. Under this assumption, a form of Bessel's equation results for which solutions are functions of radius alone. End-effect corrections may be applied later by 
use of test data or by a more extensive analysis. The rationalized system of MKS (meter-kilogram-second) units will be used in the analysis.

The ac field-strength variation in a cylindrical conductor with axial excitation will be calculated first.

The circumferential fluid conductance of a hollow cylindrical element at radius $r$ within a coil of length $b$ is given by

$$
\mathrm{dG}=\frac{\ell \mathrm{dr}}{2 \pi \mathrm{r} \rho}
$$

where $\rho$ is the resistivity of the fluid. The current in the element is

$$
d i=j \omega \varphi d G \text {, }
$$

where $\varphi$ is the flux linking the element. Or, from Eq. 12,

$$
\mathrm{di}=j \omega \varphi \frac{\ell \mathrm{dr}}{2 \pi \mathrm{r} \rho} .
$$

But, by Ampere's law (in rationalized units),

$$
\mathrm{di}=\ell(\mathrm{H}+\mathrm{dH})-\ell \mathrm{H}=\ell \mathrm{dH},
$$

where $H$ is the axial component of field strength just inside the element, and $\mathrm{dH}$ is the change over its thickness. From Eqs. 14 and 15 ,

$$
\varphi=\frac{2 \pi \rho}{j \omega} \mathbf{r} \frac{\mathrm{dH}}{\mathrm{dr}}
$$

Differentiating gives

$$
\frac{d \varphi}{d r}=\frac{2 \pi \rho}{j \omega}\left(r \frac{d^{2} H}{d r^{2}}+\frac{d H}{d r}\right)
$$

But

$$
\mathrm{d} \varphi=2 \pi \mu \mathrm{Hr} d r
$$

where $\mu$ is the permeability. of the fluid, or

$$
\frac{\mathrm{d} \varphi}{\mathrm{dr}}=2 \pi \mu \mathrm{Hr} .
$$


So, from Eq. 17,

$$
\frac{j \omega \mu}{\rho} \mathrm{Hr}=\mathrm{r} \frac{\mathrm{d}^{2} \mathrm{H}}{\mathrm{dr}^{2}}+\frac{\mathrm{dH}}{\mathrm{dr}},
$$

or

$$
\mathrm{r}^{2} \frac{\mathrm{d}^{2} \mathrm{H}}{\mathrm{dr^{2 }}}+\mathrm{r} \frac{\mathrm{dH}}{\mathrm{dr}}-\frac{j \omega \mu \mathrm{Hr}^{2}}{\rho}=0
$$

One of the standard forms of the Bessel equation is obtained by substituting

$$
\frac{\omega \mu r^{2}}{\rho}=x^{2}
$$

Then, Eq. 21 becomes

$$
\mathrm{x}^{2} \frac{\mathrm{d}^{2} \mathrm{H}}{\mathrm{dx^{2 }}}+\mathrm{x} \frac{\mathrm{dH}}{\mathrm{dx}}-j \mathrm{Hx}^{2}=0
$$

or

$$
\frac{d^{2} H}{d x^{2}}+\frac{1}{x} \frac{d H}{d x}-j H=0 .
$$

The general solution of Eq. 24 is

$$
H=C_{1}[\operatorname{ber}(x)+j \operatorname{bei}(x)]+C_{2}[\operatorname{ker}(x)+j \operatorname{kei}(x)],
$$

where ber $(x)$, bei $(x), \operatorname{ker}(x)$, and $\operatorname{kei}(x)$ are the Kelvin functions of zero order (from p. 379 of Ref. 7). At the axis of the conduit,

$$
\mathrm{x}=\mathrm{r}=0,
$$

and

$$
\mathrm{H}=\mathrm{H}_{0} .
$$

From p. 431 of Ref. 7,

$$
\begin{aligned}
\operatorname{ber}(0) & =1.0, \\
\operatorname{bei}(0) & =0, \\
\operatorname{ker}(0) & =\infty,
\end{aligned}
$$

and

$$
\operatorname{kei}(0)=-\pi / 4
$$


Since $\mathrm{H}_{0}$, the field at the axis, is finite,

$$
\mathrm{C}_{2}=0
$$

and

$$
\mathrm{C}_{1}=\mathrm{H}_{0}
$$

Therefore,

$$
H=H_{0}[\operatorname{ber}(x)+j \operatorname{bei}(x)]
$$

or, if the complete complex variable is denoted by be( $x)$,

$$
\mathrm{H}=\mathrm{H}_{0} \mathrm{be}(\mathrm{x}) \text {. }
$$

In line with the signal-per-section system of analysis, it will be assumed that the axial field component at the fluid surface is the same in magnitude at each primary-secondary juncture. With a limited number of sections, this assumption is not strictly true. For example, in Fig. 3, the surface field at the $d_{1} g_{1}$ juncture is somewhat smaller than that at the $d_{2} g_{2}$ juncture, since the $d_{3}$ section adds somewhat to the field produced by $d_{2}$. This error will become smaller as the number of sections is increased, since it applies mainly to the end sections. Even with a limited number of sections, an average field value can be selected to minimize errors.

An important consequence of the above assumption is that all the axial flux issuing from the end of a primary section becomes the radial flux linking the fluid within a secondary section. Calculation of the radial flux in the fluid inside a secondary coil then becomes a simple matter.

The flux within a radius $r_{1}$ at the end of a primary coil is given by

$$
\varphi_{1}=\int_{0}^{r_{1}} 2 \pi \mu r H_{d} d r,
$$

where $\mathrm{H}_{\mathrm{d}}$ is the axial field intensity at the end of a primary coil at radius $r$.

From Eq. 22,

$$
\varphi=\frac{2 \pi \rho}{\omega} \int_{0}^{x_{1}} H_{d} x d x
$$

where

$$
x_{1}=\sqrt{\frac{\omega \mu}{\rho}} r_{1}
$$


and, from Eq. 34,

$$
\varphi=\frac{2 \pi p}{\omega} \mathrm{H}_{0 \mathrm{~d}}\left[\int_{0}^{\mathrm{x}_{1}} \operatorname{ber}(\mathrm{x}) \mathrm{x} \mathrm{dx}+\mathrm{j} \int_{0}^{\mathrm{x}_{1}} \operatorname{bei}(\mathrm{x}) \mathrm{xdx}\right],
$$

where $\mathrm{H}_{0 \mathrm{~d}}$ is the field at the axis of the primary coil. From p. 380 of Ref. 7,

$$
\int \operatorname{ber}(x) x d x=x \frac{d}{d x} \operatorname{bei}(x)
$$

and

$$
\int \operatorname{bei}(x) x d x=-x \frac{d}{d x} \operatorname{ber}(x)
$$

Thus, dropping the 1 subscripts of $\mathrm{x}$ in Eq. 38 after applying the limits of integration results in

$$
\varphi=\frac{2 \pi \rho H_{0 d}}{\omega} \times\left[\frac{d}{d x} \operatorname{bei}(x)-j \frac{d}{d x} \operatorname{ber}(x)\right],
$$

or

$$
\varphi=\frac{2 \pi \rho H_{0 d}}{\omega} x(-j) \frac{d}{d x} b e(x)
$$

The average radial component of magnetic induction inside a secondary coil at radius $r$ is

$$
B_{r}=\frac{\varphi}{2 \pi r l_{g}}
$$

where $l_{g}$ is the length of one secondary coil section. Using the variable transformation, Eqs. 22 and 41, produces

$$
B_{r}=\sqrt{\frac{\mu \rho}{\omega}} \frac{H_{0 d}}{l_{g}}(-j) \frac{d}{d x} \text { be }(x) .
$$

The field at the axis can be related to that at the outside surface by use of Eq. 35. Thus,

$$
B_{r}=\sqrt{\frac{\mu \rho}{\omega}} \frac{H_{s d}}{l_{g}}(-j) \frac{\frac{d}{d x} b e(x)}{b e\left(x_{s}\right)}
$$


where $\mathrm{H}_{\mathbf{S}}$ is the field strength at the outside fluid surface at the primarysecondary interface and is given by

$$
\mathrm{H}_{\mathrm{sd}}=\mathrm{K}_{\mathrm{ihd}} \frac{\mathrm{N}_{\mathrm{d}} \mathrm{I}_{\mathrm{d}}}{\mathrm{D}_{\mathrm{c}}}
$$

where $\mathrm{N}_{d}$ is the number of turns in a primary section, $\mathrm{D}_{\mathrm{C}}$ is the channel diameter, $I_{d}$ is the primary current, and $K_{i h d}$ is a real, dimensionless constant depending on the system geometry. Thus, in terms of the primary current,

$$
\left.B_{r}=\sqrt{\frac{\mu \rho}{\omega}} \frac{K_{i h d} N_{d} I_{d}}{D_{c} l_{g}} ;-j\right) \frac{\frac{d}{d x} b e(x)}{b e\left(x_{s}\right)} .
$$

If a current of the same frequency as that of the primary current is made to flow in the secondary coils, the resulting induced currents in the fluid react with the radial induction of Eq. 46 to produce an axial force on the fluid. Use of these hypothetical currents and forces with the reciprocity principle yields the sensitivity factor of the flowmeter as actually used.

The cur rent in a hollow cylindrical element of the fluid within a secondary coil is, from Eqs. 15 and 35,

$$
d I=l_{g} H_{0 g} \frac{d}{d x} b e(x) d x
$$

where $l_{g}$ is the length of a secondary coil and $H_{0 g}$ is the field at the axis due to the secondary coil current.

Using the relations between secondary surface field and secondary coil current, and between the axial and surface fields, as was done for the primary, produces

$$
d I=\frac{N_{g} I_{g} K_{i h g} \ell_{g}}{D_{c}} \frac{\frac{d}{d x} b e(x) d x}{b e\left(x_{s}\right)},
$$

or

$$
\frac{d I}{I_{g}}=\frac{N_{g} K_{i h g} \ell_{g}}{D_{c}} \frac{\frac{d}{d x} b e(x) d x}{b e\left(x_{s}\right)} .
$$

The circumference of the element, using the variable transformation Eq. 22, is

$$
2 \pi r=2 \pi x \sqrt{\frac{\rho}{\omega \mu}} .
$$


The product of Eqs. 46, 49, and 50 gives the force per primary current. Thus,

$$
\left[\frac{d F}{I_{g}}\right]=\frac{2 \pi p}{\omega} \frac{K_{i h d} K_{i h g} N_{d} N_{g} I_{d}}{D_{c}^{2}}(-j) \frac{\left[\frac{d}{d x} b e(x)\right]^{2} x d x}{\left[b e\left(x_{s}\right)\right]^{2}} .
$$

From Eq. 22

$$
x^{2}=\frac{2 \pi f \mu r^{2}}{\rho}=\frac{2 f \mu A}{\rho}
$$

where $\mathrm{A}$ is the area enclosed by the element. So,

$$
\mathrm{x} d \mathbf{x}=\frac{f \mu}{\rho} \mathrm{dA}
$$

where $\mathrm{dA}$ is the area of the element. The area, $\mathrm{A}_{C}$, of the channel is related to its diameter, $D_{C}$, by

$$
D_{c}^{2}=\frac{4}{\pi} A_{C}
$$

Thus, applying Eqs. 53 and 54 to Eq. 51 produces

$$
\left[\frac{\mathrm{dF}}{\mathrm{I}_{\mathrm{g}}}\right]=\frac{\pi}{4} \mu \mathrm{K}_{\mathrm{ihd}} \mathrm{K}_{\mathrm{ihg}} \mathrm{N}_{\mathrm{d}} \mathrm{N}_{\mathrm{g}} \mathrm{I}_{\mathrm{d}}(-\mathrm{j}) \frac{\left[\frac{\mathrm{d}}{\mathrm{dx}} \mathrm{be}(\mathrm{x})\right]^{2}}{\left[\mathrm{be}\left(\dot{\mathrm{x}}_{\mathrm{S}}\right)\right]^{2}} \frac{\mathrm{dA}}{\mathrm{A}_{\mathrm{C}}} .
$$

Using reciprocity and multiplying by $\mathrm{N}_{\mathrm{dg}}$, the number of primary-secondary sections, to obtain the total signal voltage generated by a cylindrical element of fluid, we obtain

$$
d V=\frac{\pi}{4} \mu K_{i h d} K_{i h g} N_{d} N_{g} N_{d g} I_{d}(-j) \frac{\left[\frac{d}{d x} b e(x)\right]^{2}}{\left[b e\left(x_{s}\right)\right]^{2}} \frac{d A}{A_{c}} u
$$

where $u$ is the fluid velocity in the element.

The signal-profile function is defined as

$$
F_{s p}\left(x, x_{s}\right)=(-j) \cdot \frac{\left[\frac{d}{d x} b e(x)\right]^{2}}{\left[b e\left(x_{s}\right)\right]^{2}} \text {. }
$$


Thus,

$$
V=\frac{\pi}{4} \mu K_{i h d} K_{i h g} N_{d} N_{g} N_{d g} I_{d} u_{a} \sum_{A=0}^{A=A_{c}} F_{s p} \frac{u}{u_{a}} \frac{\Delta A}{A_{c}}
$$

where $u_{a}$ is the average velocity in the channel.

The factors to the left of the summation sign in Eq. 58 are combined as a normalization factor.

Thus,

$$
\mathrm{K}_{\mathrm{n}}=\frac{\pi}{4} \mu \mathrm{K}_{\mathrm{ihd}} \mathrm{K}_{\mathrm{ihg}} \mathrm{N}_{\mathrm{d}} \mathrm{N}_{\mathrm{g}} \mathrm{N}_{\mathrm{dg}} \mathrm{I}_{\mathrm{d}} \mathrm{u}_{\mathrm{a}}
$$

and

$$
V=K_{n} \sum_{A=0}^{A=A_{C}} F \operatorname{sp} \frac{u}{u_{a}} \frac{\Delta A}{A_{c}}
$$

In the computer program for $F_{s p}$ (program SIGPROF in Appendix A) and in related programs, new variables relating directly to the first power of areas, frequency, fluid permeability, and fluid resistivity, are introduced.

Thus,

$$
s=\frac{x_{s}^{2}}{2}
$$

and

$$
a=\frac{x^{2}}{2}
$$

and, from Eq. 52,

$$
s=\frac{f \mu A_{C}}{\rho}
$$

and

$$
a=\frac{f \mu A}{\rho}
$$

In Figs. 4 and 5, the in-phase and quadrature components of the signal-profile function are plotted against relative radius squared. Zero corresponds to the channel axis, and unity to its outside surface. 


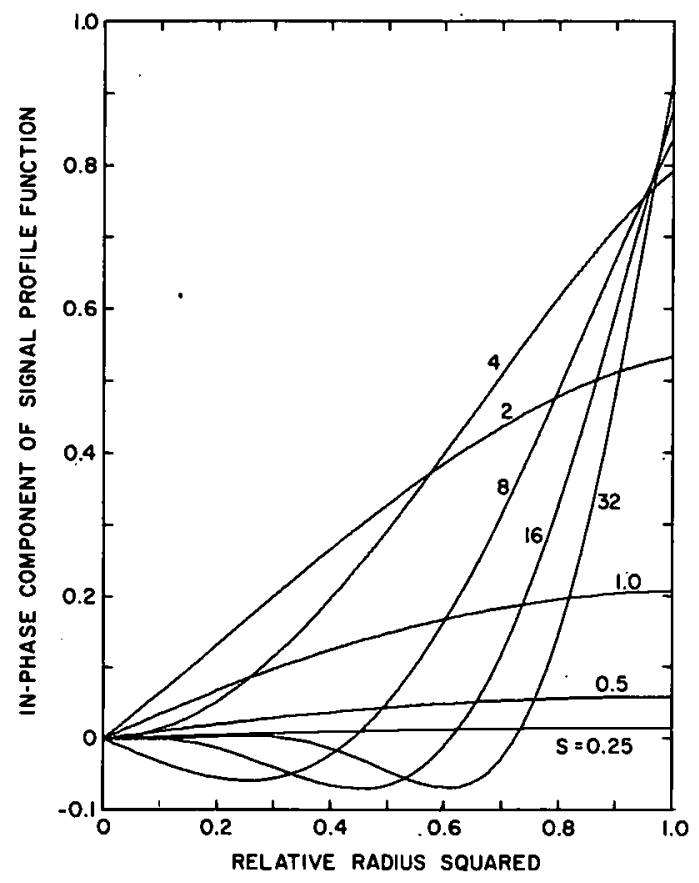

Fig. 4. In-phase Component of Signal-profile Function

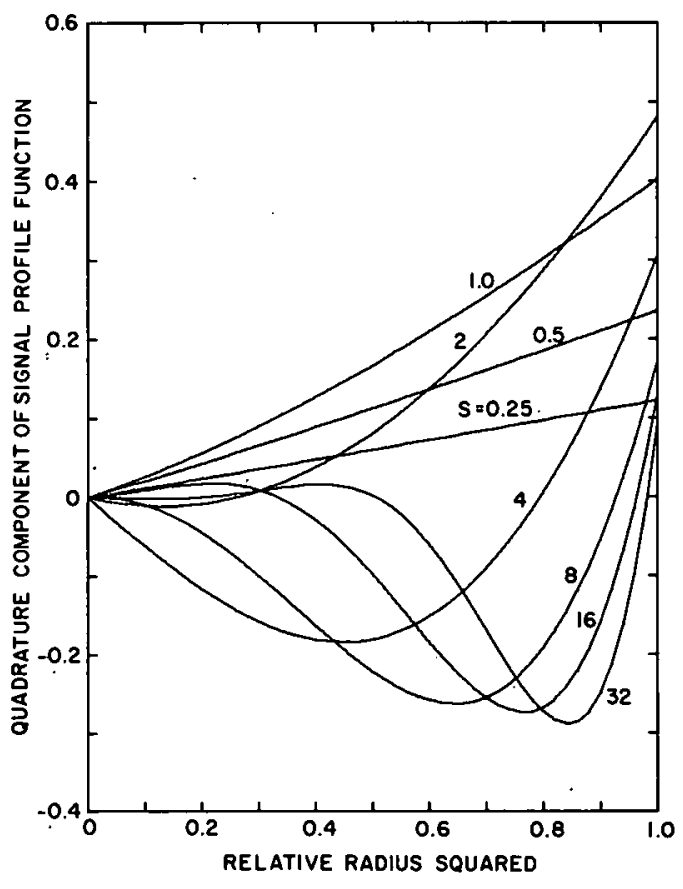

Fig. 5. Quadrature Component of Signal-profile Function

These curves, with Eq. 58, can be used to calculate the voltage for any axisymmetric velocity profile in the fluid. Signal components in phase and in quadrature with the primary current are given. From Eq. 63, the curves at various $s$ values represent different operating frequencies for given channel size and fluid properties. The field constants, $K_{i h d}$ and $K_{i h g}$ in Eqs. 58 and 59, can be calculated by the method of Brown and Flax. ${ }^{8}$

The curves of Figs. 4 and 5 give information as to the type of readout equipment required with the eddy-current flowmeter and as to desirable operating frequencies. The signal amplifier could be made to read (a) the total signal, (b) the signal component in phase with the primary current, or (c) the quadrature component, where the possible measuring systems are listed in the order of increasing complexity.

The rapidly rising curves in the region of the channel surface in Fig. 5 for the quadrature signal, coupled with the rapidly changing fluid velocity (for typical profiles) in this region, make for calibration instability due to minor changes in the surface condition of the pipe wall. Also, with portions of the curves above and below the zero line, it is easy to imagine velocity profiles that would give gross measurement errors, such as a false indication of zero flow, or even a phase reversal, yielding a false indication of reversed flow direction.

These facts, and the generally higher signal levels indicated in Fig. 4, make the selection of the in-phase component preferable. The 
concave-downward nature of the in-phase curves for $s$ values less than 4 reduces the sensitivity to conditions of the pipe wall, and tends to give a better measurement of total flow, in spite of a changing velocity profile.

In Fig. 5, a net positive area is shown for curves for $s=2$ and lower, and net negative areas for $s=4$ and higher. We can expect that an $s$ value exists between 2 and 4 for which the net area is zero. If an operating frequency is chosen corresponding to this $s$ value, the quadrature signal (for uniform fluid velocity) is zero and the total signal is in phase with the primary current.

It is also evident from Fig. 4 that the in-phase component has a maximum area for $\mathrm{s}$ between 2 and 4 . The desirability of choosing the operating frequency providing an in-phase signal is quite clear. Not only is the signal a maximum here, but the signal-conditioning equipment is greatly simplified by the elimination of the quadrature component. In particular, operation of a phase-sensitive detector with a primary-current reference is more reliable in the absence of the quadrature signal.

At this point, these conclusions hold, strictly, for uniform fluid velocity only. However, a condition of near-zero phase shift and signal maximum holds for a wide range of velocity profiles at a particular $s$ value or operating frequency.

A degree of nonlinearity is introduced into the flowmeter response by the combined effects of a radius-sensitive signal (Figs. 4 and 5) and a velocity profile that changes with the average flow velocity. In the next section, velocity profiles are developed for a range of Reynolds numbers for the fluid. The velocity-profile data are then combined with the signalprofile relations to give the flowmeter response as a function of volume rate and operating frequency.

\section{VELOCITY. PROFILES}

Flowmeters in liquid-metal reactor systems typically operate with the fluid in the turbulent condition. Various relations (some with analytic. foundations) have been used to characterize the velocity profiles at various Reynolds numbers. A simple power law, empirically adjusted to fit test data, is sufficient for our purpose and is convenient to use.

Knudsen and Katz (p. 149 of Ref. 9) plotted a wide range of data from various investigators showing the variation of the ratio of average to maximum velocity with Reynolds numbers on semilogarithmic scales. In the turbulent region, the data points fit a straight line very closely. That is,

$$
\frac{u_{a}}{u_{m}}=A+B \log R e
$$


where $u_{a}$ and $u_{m}$ are the average and maximum velocities. The values

$$
A=0.655
$$

and

$$
\mathrm{B}=0.035 \text {. }
$$

fit the straight part of the curve. Thus,

$$
\frac{\mathrm{u}_{\mathrm{a}}}{\mathrm{u}_{\mathrm{m}}}=0.655+0.035 \log \mathrm{Re}
$$

When an empirical relation is chosen for the fluid velocity at intermediate radii, condition. 68 must be fulfilled, and, for continuity at the axis, the slope of the velocity-radius curve should be zero at zero radius. The following relation meets the requirement for zero slope at the axis and can be made to meet condition 68 through the proper choice of the exponent $n$ :

$$
\mathrm{u}=\mathrm{u}_{\mathrm{m}}\left[1-\left(\frac{\mathrm{r}}{\mathrm{R}}\right)^{\mathrm{n}}\right]
$$

where $R$ is the channel radius, and $u$ is the velocity at radius $r$.

The area integral of the velocity must equai the average velocity times the channel area. That is,

$$
\int \mathrm{udA}=\mathrm{A}_{\mathrm{c}} \mathrm{u}_{\mathrm{a}}
$$

where $A_{C}$ is the channel area.

In terms of the radius and our assumed velocity relation,

$$
\int_{0}^{R} u_{m}\left[1-\left(\frac{r}{R}\right)^{n}\right] 2 \pi r d r=\pi R^{2} u_{a}
$$

or

$$
\int_{0}^{R}\left[1-\left(\frac{r}{R}\right)^{n}\right] r d r=\frac{R^{2} u_{a}}{2 u_{m}}
$$

Integration of Eq. 72 yields

$$
\mathrm{n}=\frac{2 \frac{\mathrm{u}_{\mathrm{a}}}{\mathrm{u}_{\mathrm{m}}}}{1-\frac{\mathrm{u}_{\mathrm{a}}}{\mathrm{u}_{\mathrm{m}}}}
$$


A normalized form of Eq. 69 is

$$
\frac{\mathrm{u}}{\mathrm{u}_{\mathrm{a}}}=\frac{1}{\frac{\mathrm{u}_{\mathrm{a}}}{\mathrm{u}_{\mathrm{m}}}}\left[1-\left(\frac{\mathrm{r}}{\mathrm{R}}\right)^{\mathrm{n}}\right]
$$

or, in terms of the relative area,

$$
\frac{\mathrm{u}}{\mathrm{u}_{\mathrm{a}}}=\frac{1}{\frac{\mathrm{u}_{\mathrm{a}}}{\mathrm{u}_{\mathrm{m}}}}\left[1-\left(\frac{\mathrm{A}}{\mathrm{A}_{\mathrm{c}}}\right)^{\mathrm{m}}\right]
$$

where $A_{C}$ is the channel area and $A$ is the partial area. That is,

$$
\begin{aligned}
& A=\pi r^{2}, \\
& A_{c}=\pi R^{2},
\end{aligned}
$$

and

$$
\mathrm{m}=\frac{\mathrm{n}}{2}=\frac{\frac{\mathrm{u}_{\mathrm{a}}}{\mathrm{u}_{\mathrm{m}}}}{1-\frac{\mathrm{u}_{\mathrm{a}}}{\mathrm{u}_{\mathrm{m}}}}
$$

From Eqs. 63 and 64, Eq. 75 may be written in terms of the previously defined variables as follows:

$$
\frac{u}{u_{a}}=\frac{1}{\frac{u_{a}}{u_{m}}}\left[1-\left(\frac{a}{s}\right)^{m}\right] \text {. }
$$

Since $u_{a} / u_{m}$ is given by Eq. 68 , the velocity profile for the turbulent flow condition is determined.

At low volume rates, the flow may become laminar, in which case the velocity profile becomes parabolic (p. 86 of Ref. 9).

In our notation,

$$
u=2 u_{a}\left[1-\left(\frac{r}{R}\right)^{2}\right]=2 u_{a}\left(1-\frac{a}{s}\right),
$$

or

$$
\frac{\mathrm{u}}{\mathrm{u}_{\mathrm{a}}}=2\left(1-\frac{\mathrm{a}}{\mathrm{s}}\right)
$$

By a comparison with Eq. 79, as the fluid drops into the laminar condition, the exponent $\mathrm{m}$ takes on the constant value 1 , and $\mathrm{u}_{\mathrm{a}} / \mathrm{u}_{\mathrm{m}}$ becomes $1 / 2$.. 
Table I shows the variations of the parameters describing the velocity profile.

TABLE I. Velocity-profile Variables

\begin{tabular}{|c|c|c|c|c|c|c|c|}
\hline \multirow[b]{2}{*}{$\mathrm{Re}$} & \multirow[b]{2}{*}{ Flow Condition } & \multicolumn{2}{|l|}{$\mathrm{u}_{\mathrm{a}}$} & \multirow[b]{2}{*}{$\mathrm{Re}$} & \multirow[b]{2}{*}{ Flow Condition } & \multicolumn{2}{|l|}{$\mathrm{u}_{\mathrm{a}}$} \\
\hline & & $u_{m}$ & $\mathrm{~m}$ & & & $\overrightarrow{u_{m}}$ & $\mathrm{~m}$ \\
\hline$<4 \times 10^{3}$ & Laminar & 0.500 & 1.00 & $1 \times 10^{6}$ & Turbulent & 0.865 & 6.41 \\
\hline $4 \times 10^{3}$ & Turbulent & 0.781 & 3.57 & $2 \times 10^{6}$ & Turbulent & 0.876 & 7.03 \\
\hline $1 \times 10^{4}$ & Turbulent & 0.795 & 3.88 & $4 \times 10^{6}$ & Turbulent & 0.861 & 7.78 \\
\hline $2 \times 10^{4}$ & Turbulent & 0.806 & 4.14 & $1 \times 10^{7}$ & Turbulent & 0.900 & 9.00 \\
\hline $4 \times 10^{4}$ & Turbulent & 0.816 & 4.37 & $2 \times 10^{7}$ & Turbulent & 0.911 & 10.18 \\
\hline $1 \times 10^{5}$ & Turbulent & 0.830 & 4.88 & $4 \times 10^{7}$ & Turbulent & 0.921 & 11.67 \\
\hline $2 \times 10^{5}$ & Turbulent & 0.841 & 5.27 & $1 \times 10^{8}$ & Turbulent & 0.935 & 14.38 \\
\hline $4 \times 10^{5}$ & Turbulent & 0.851 & 5.71 & $\infty$ & Uniform & 1.000 & $\infty$ \\
\hline
\end{tabular}

Figures 6 and 7 show velocity profiles on the basis of radius and area, respectively.

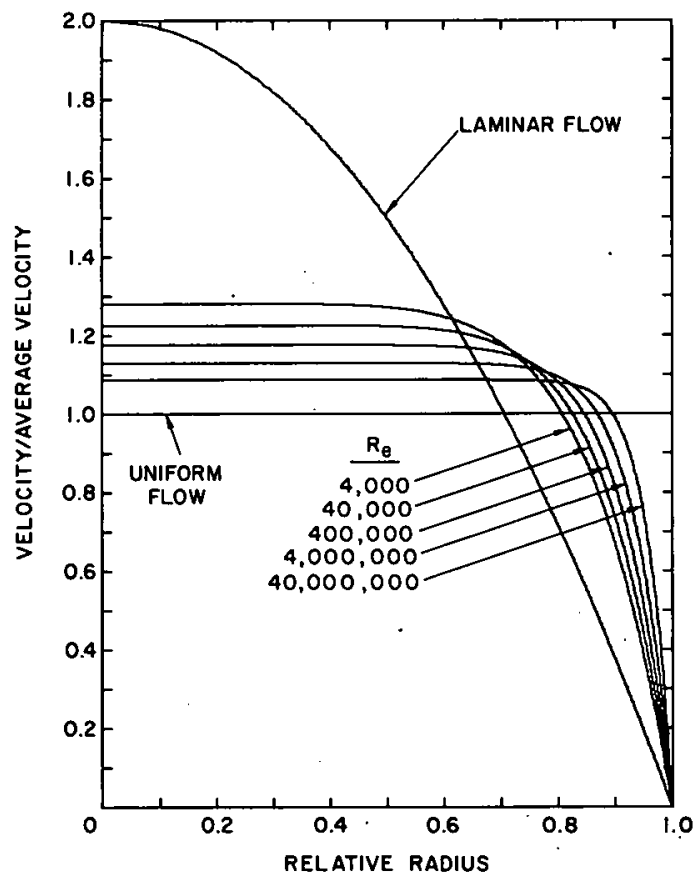

Fig. 6. Velocity Profiles, Radius Base

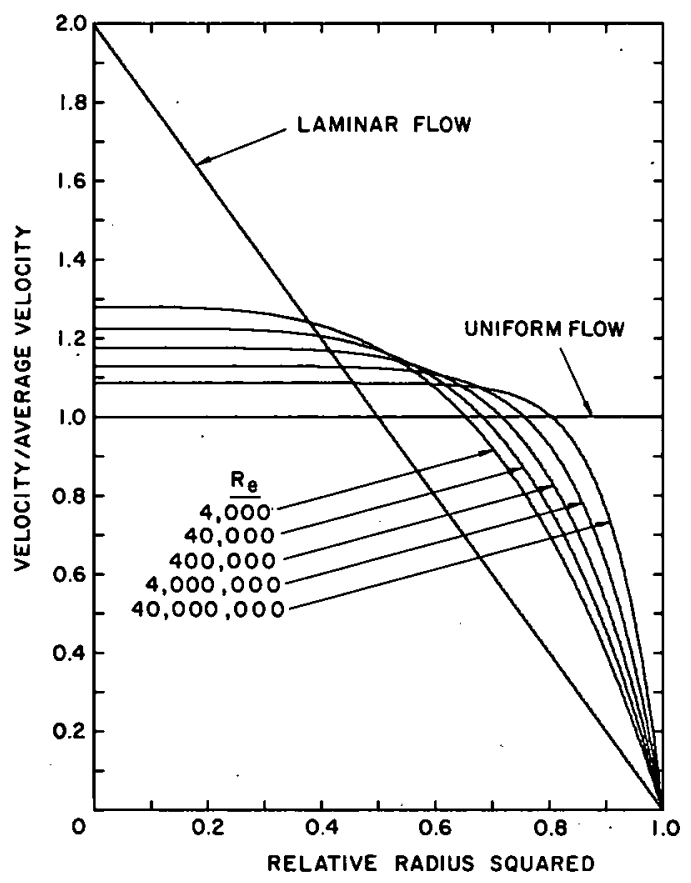

Fig. 7. Velocity Profiles, Area Base

\section{VARIATION OF SIGNAL WITH REYNOLDS NUMBER AND FREQUENCY}

In program FLOMGEN (Appendix B), Eqs. 57, 68, 78, 79, and 81 are used to perform the summation indicated in Eq. 60. Separate program branches are used for the laminar, turbulent, and uniform flow conditions.

In calculating the signal-profile function, we use the following expansion: 


$$
-j\left[\frac{d}{d x} \operatorname{be}(x)\right]^{2}=2 d b e r(x) d b e i(x)+j\left[\operatorname{dbei}^{2}(x)-\operatorname{dber}^{2}(x)\right]
$$

where

$$
\operatorname{dber}(x)=\frac{d}{d x} \operatorname{ber}(x)
$$

and

$$
\operatorname{dbei}(x)=\frac{d}{d x} \operatorname{bei}(x)
$$

The subroutines for all programs are shown separately in Appendix E. Those for the Bessel functions and their derivatives use polynomial approximations of eight terms, yielding an accuracy to about 1 in $10^{8}$.

The programs were written to be compatible with the CDC $160 \mathrm{~A}$ and CDC 3600 computers. Sums of 25 increments were used on the $160 \mathrm{~A}$, and 250 increments on the 3600: The small difference shown where the same program was run on both computers indicates that the 250 -term sum is accurate to a fraction of $1 \%$.

Complex variables were manipulated through the TORECT and TOPOLR subroutines, which convert from the polar to the rectangular forms and vice versa. Additions were performed in the rectangular form, and multiplications in the polar form.

Program FLOMGEN gives solutions of the normalized voltage function, $V_{n}$, in rectangular and polar forms. $V_{n}$ is the summation term in Eq. 60. In the program, VR, VI, VS, and VA indicate the real component, imaginary component, magnitude, and phase angle of the function, respectively. The primary current, $I_{d}$, is the reference.

Values of $s$ in geometric steps of $2^{1 / 6}$ covering the range 0.25 through 32.0 are shown in the output of the program. For each s, solutions are given for laminar flow, uniform flow, and turbulent flow for Reynolds numbers from 4000 (the approximate lower limit for turbulent flow) through $10^{7}$. The $4,10,20,40$ system of increase is used here. The normalized voltage function is plotted in Figs. 8-11.

The phase angle of the signal, VA, for all flow conditions goes through zero within the range of $\mathrm{s}$ values, 2.51984 to 3.17480 . Also, the in-phase signal, VR, and the signal magnitude, VS, have maximums in this s range.

Other advantages, more important than mere high signal levels, result if operating conditions are selected to give an $s$ value near a signal maximum. These advantages are apparent from a study of the $s$ variable, as defined in Eq. 63. 


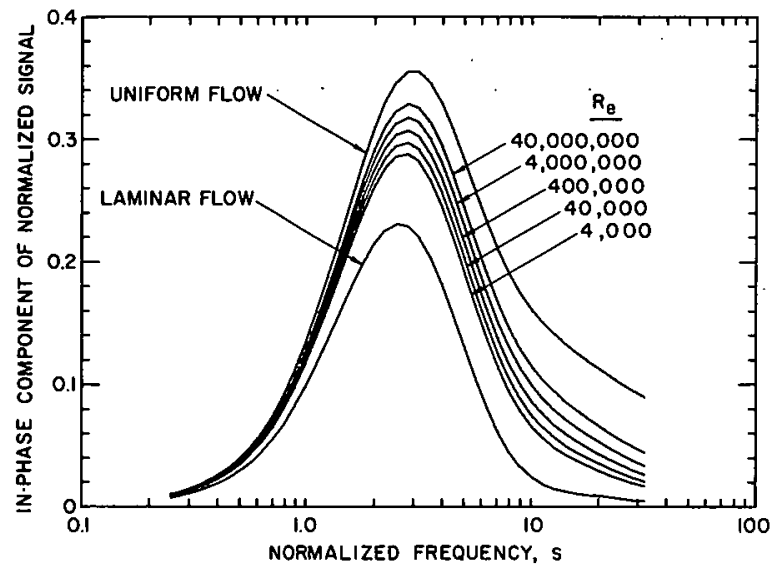

Fig. 8. In-phase Component of Normalized Signal

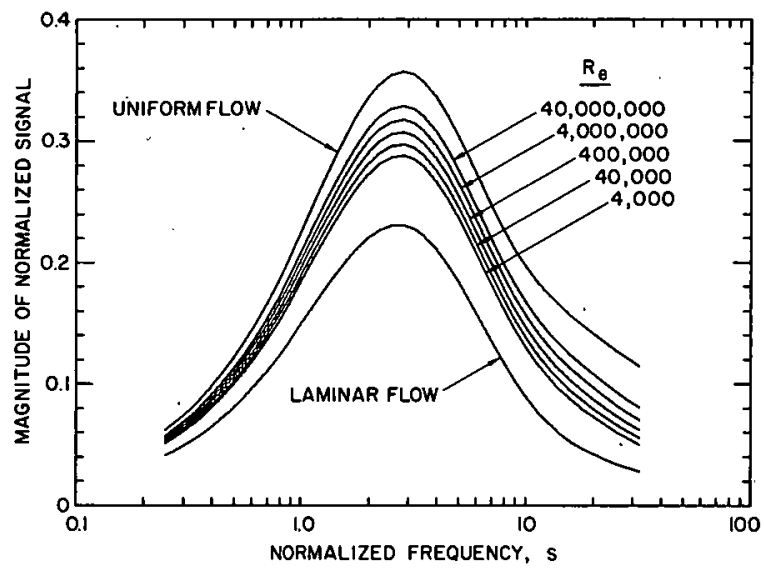

Fig. 10. Magnitude of Normalized Signal

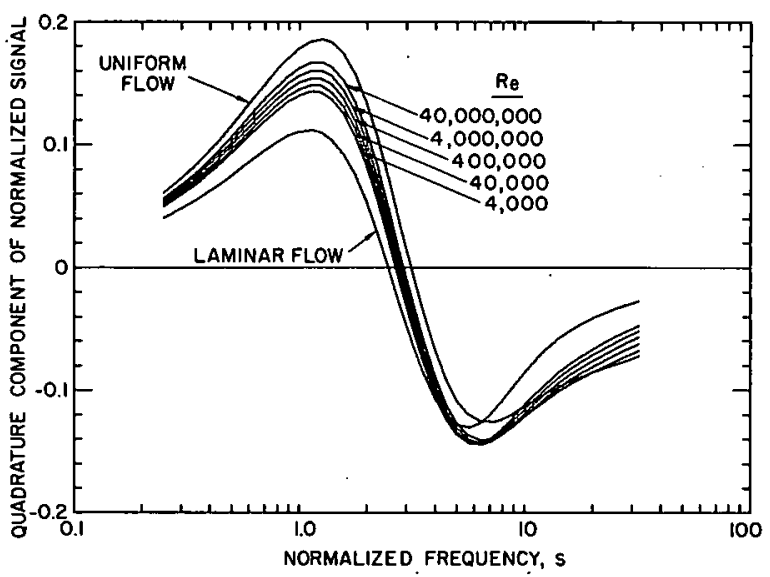

Fig. 9. Quadrature Component of Normalized Signal

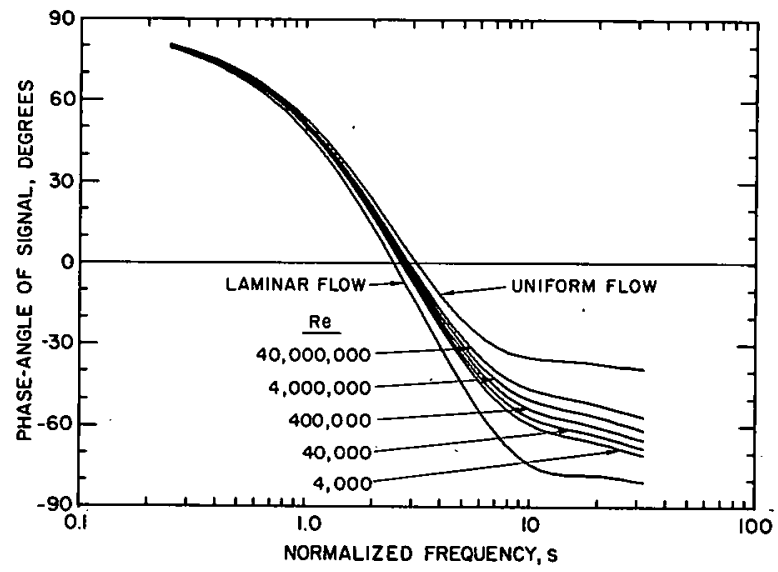

Fig. 11. Phase Angle of Signal

With $s$ in the region of a signal maximum, calibration changes due to unknown variations in any of the parameters making up the $s$ variable are minimized. For example, the requirement on the stability of the carrier frequency supply are made less stringent than when operating with $s$ in an offmaximum region, where small variations in $s$ cause much greater variations in signal level. This philos ophy applies particularly to the matter of temperature errors, which are investigated in the next section.

Certain disadvantages of using the quadrature signal are apparent from Fig. 9. Either the signal maximum, in the region slightly above $\mathbf{s}=$ 1.0 , or the signal minimum, near $s=7.0$, could be selected as operating points. The smaller spread of the curves about the negative peak makes this operating condition the preferable one. In either case, broad swings in fluid resistivity under transient temperature conditions could move the operating point along the steep curves between the positive and negative peaks and give a false indication of a flow reversal. 
This fact, the higher signal levels shown for the in-phase or total signals, and the greater complexity of the equipment that would be required for selecting the quadrature signal component, make the use of the in-phase or total signal preferable.

As mentioned previously, zero-phase, and maximum in-phase and total signals occur for $\mathrm{s}$ values in the range $2.51984 \leq \mathrm{s} \leq 3.17480$. The lower and higher limits represent the zero-phase condition for the laminar and uniform flow conditions, respectively.

Table II shows the range of operating frequencies giving the higher $s$ value for a range of channel diameters, for sodium at $400^{\circ} \mathrm{C}(\rho=0.2193 \mathrm{x}$ $10^{-6}$ ohm-meter).

TABLE II. Optimum Operating Frequencies for Sodium at $400^{\circ} \mathrm{C}$

\begin{tabular}{lcc|ccc}
\hline Channel Diameter & Frequency, & \multicolumn{2}{c}{ Channel Diameter } & Frequency, \\
\hline Inches & Meters & Inches & Meters & Hz \\
\hline 0.32 & 0.0081 & 10680 & 4.0 & 0.1016 & 68.34 \\
0.40 & 0.0102 & 6834 & 5.0 & 0.1270 & 43.74 \\
0.50 & 0.0127 & 4374 & 6.4 & 0.1626 & 26.70 \\
0.64 & 0.0163 & 2670 & 8.0 & 0.2032 & 17.09 \\
0.80 & 0.0203 & 1709 & 10.0 & 0.2540 & 10.94 \\
1.00 & 0.0254 & 1094 & 12.5 & 0.3175 & 7.000 \\
1.25 & 0.0318 & 700.0 & 16 & 0.4064 & 4.271 \\
1.6 & 0.0406 & 427.1 & 20 & 0.5080 & 2.734 \\
2.0 & 0.0508 & 273.4 & 25 & 0.6350 & 1.750 \\
2.5 & 0.0635 & 175.0 & 32 & 0.8128 & 1.068 \\
3.2 & 0.0813 & 106.8 & & & \\
\hline
\end{tabular}

The low operating frequencies at the larger channel diameters may lead to serious response-time limitations. In these cases, there may be an advantage in using the quadrature signal at the negative response peak (Fig. 9), where the operating frequencies are about 2.2 times those shown in Table II. The greater complexity of temperature-compensation and quadrature-signal.selecting equipment may be justified with flowmeters for large-diameter channels.

Another method of avoiding the extremely low frequencies at the large diameters is to use a series of encapsulated sensors of the type described by Lehde and Lang ${ }^{1}$ at different radii in the flow channel, and to average the signals. The operating frequency should be as low as possible, consistent with response time requirements and signal levels. Although Figs. 4 and 5 hold, strictly, only for the construction using the internal field 
of a coil system external to the flow channel, the extreme sensitivity to conditions very near the flow boundary at high operating frequencies will hold for the stream-immersed coil system as well.

\section{TEMPERATURE ERRORS}

Temperature errors in the eddy-current flowmeter occur in two ways: (1) A change in resistivity of the fluid changes the $s$ value for a given operating frequency; (2) changes in the viscosity and density of the fluid change the Reynolds number for a given volume $r$ ate and thereby change the velocity distribution of the fluid and, consequently, the generated signal level. The second effect is usually quite small, but is included in the calculations (see program FLOMTEMP, Appendix C).

A reference temperature is selected $\left(400^{\circ} \mathrm{C}\right.$ in program FLOMTEMP) near the middle of an expected operating temperature range. A desirable $s$ for fluid conditions at the reference temperature is chosen $\left(s 400=2 \times 2^{2 / 3}\right.$ in program FLOMTEMP). In effect, this selection of $s$ sets the operating frequency.

To provide for a range of normalized volume rates, a range of Reynolds numbers for fluid conditions at the reference temperature (RE400 in FLOMTEMP) is selected.

The fluid properties (resistivity, density, and viscosity) for a selected set of fluid temperatures have been calculated. ${ }^{10}$ These values are used to determine the $s$ value (for fixed frequency) and the Reynolds number (for the flow held at the particular RE400 value). The normalized signal levels are then calculated for each selected temperature. The complex components VR, VI, VS, and VA show the variation of the in-phase and out-ofphase components and the magnitude and phase of the normalized signal.

The values for $\mathrm{RE} 400=4000$ are unreliable for temperatures below the reference temperature $\left(400^{\circ} \mathrm{C}\right)$ since the actual Reynolds number drops significantly below the limiting value for turbulence in this region.

The temperature effects for various flow conditions are shown in Figs. 12-15. The rising curves in Fig. 13 ranging from negative to positive signal values for all flow conditions indicate an essentially uncompensatable temperature effect for the quadrature signal at the chosen value of s400. Of course, the $\$ 400$ value was deliberately chosen to make the quadrature signal zero in the midtemperature range. Figure 13, therefore, presents a very pessimistic picture of the quadrature-signal performance. These curves are included only for completeness. 


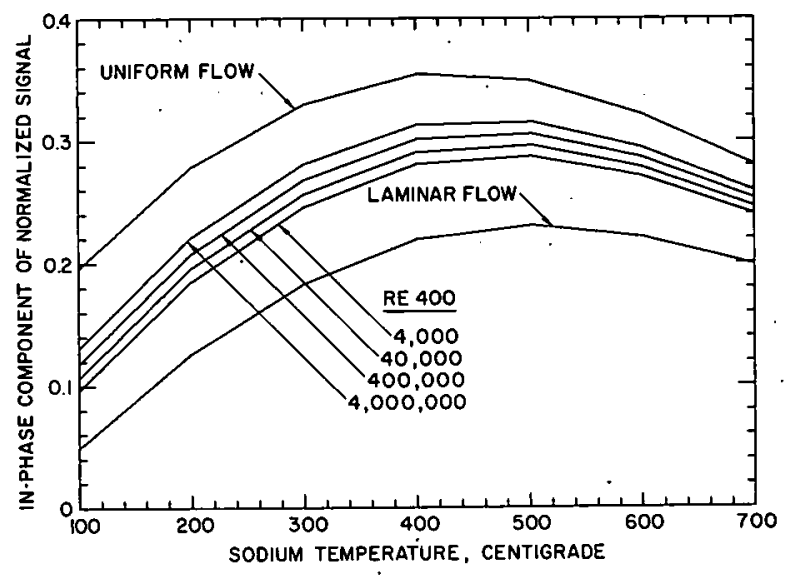

Fig. 12. Temperature Variation of In -phase Component

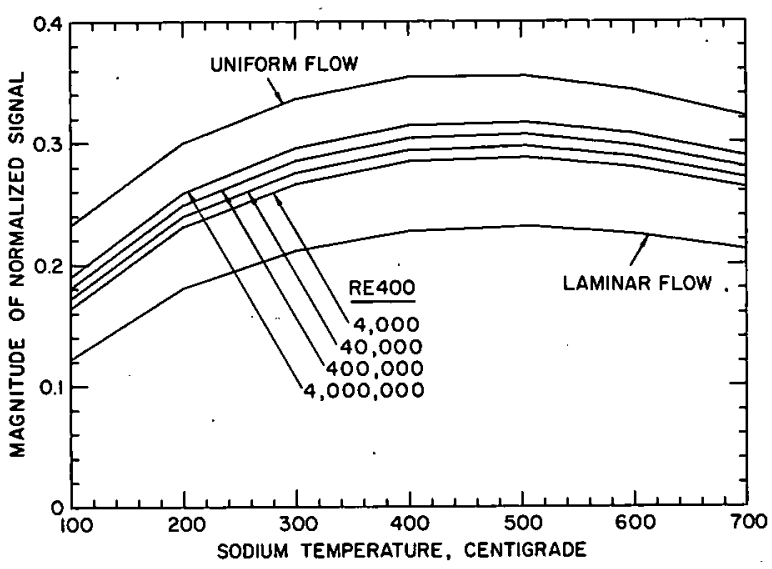

Fig. 14. Temperature Variation of Signal Magnitude

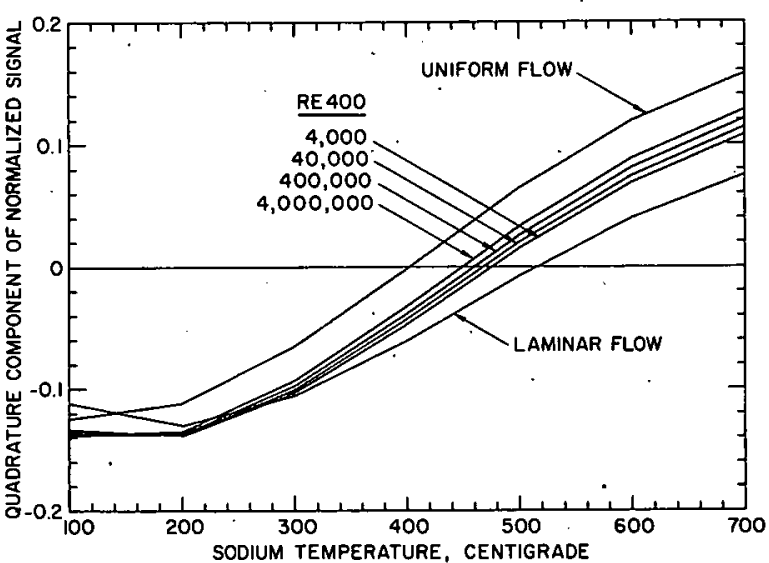

Fig. 13. Temperature Variation of Quadrature Component

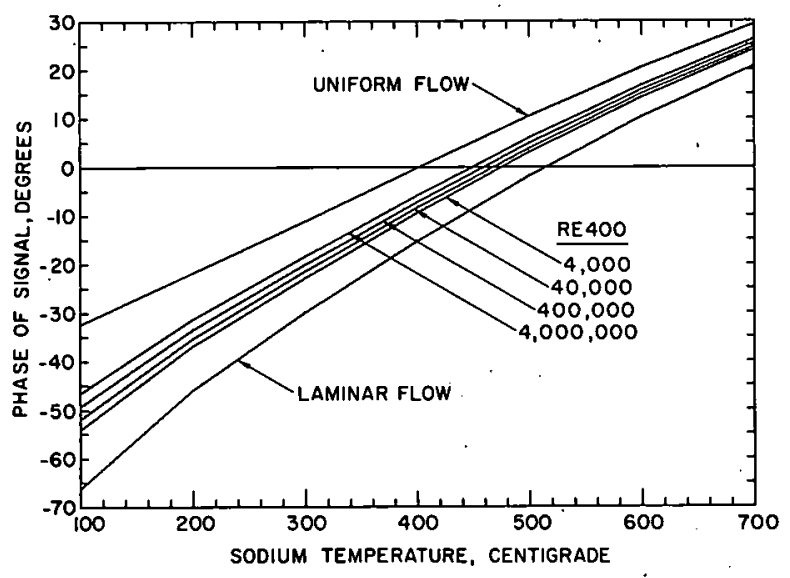

Fig. 15. Temperature Variation of Signal Phase

Table III summarizes the effects of temperature on the in-phase and total signals. These data are for constant-frequency operation with no form. of temperature compensation.

TABLE III. Uncompensated Temperature Errors

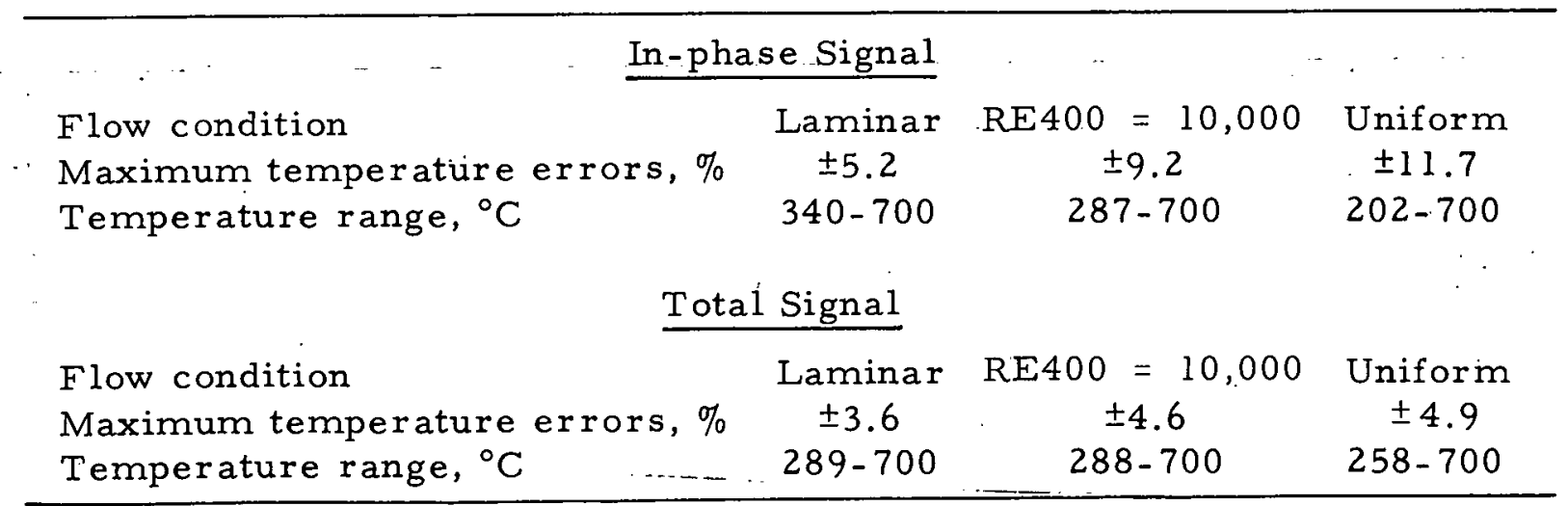


If the full temperature ranges indicated are to be accommodated, the errors may be too high, particularly if the in-phase signal is selected. Some form of temperature compensation may be required.

An effective way of eliminating the major portion of the temperature errors is to vary the frequency in a manner that keeps the $s$ variable constant. From Eq. 63, constant s requires that the frequency vary inversely with the resistivity. The fluid resistivity could be calculated from a measured temperature and the frequency adjusted accordingly. A much simpler method is to choose the $s$ value (about 2.82 ) that provides zero phase angle in the output signal. This value of $s$ is maintained, despite temperature variations, merely by adjusting the frequency to keep the output signal in phase with the exciting current. With this mode of operation, sensitivity is near maximum, and undesirable effects of quadrature-signal components are eliminated. For example, a flow reversal is indicated by a complete $180^{\circ}$ reversal of the signal relative to the exciting current. The modulated carrier can be converted to a dc signal indicating the direction and magnitude of the flow by the use of a simple ring demodulator.

\section{EFFECT OF PIPE WALL}

Induced currents in the metal pipe carrying the fluid inside the test coils result in different magnetic fields inside and outside the pipe. In calculating the effect, we will assume that the pipe is thin enough that the current density over its thickness is essentially uniform.

The circumferential conductance of a length $\ell$ of the pipe is

$$
G_{p}=\frac{l t}{2 \pi \rho_{p}\left(R-\frac{t}{2}\right)},
$$

where $t$ is the pipe thickness, $\rho_{p}$ its resistivity, and $R$ is the inside radius, or channel radius, as before.

Uniform current density, as assumed, means that the flux in the pipe is negligible, and

$$
i=j \omega \varphi G_{p}
$$

where $\varphi$ is the flux in the fluid, as before.

The total flux is obtained by replacing $x^{\circ}$ in Eq. 41 by $x_{S}$ and $\rho$ by $\rho_{\mathrm{f}}$ to distinguish from pipe resistivity $\rho_{\mathrm{p}}$. The result is 


$$
\varphi=\frac{2 \pi \rho_{f} H_{0 d}}{\omega} x_{S}(-j) \frac{d}{d x} b e\left(x_{s}\right)
$$

or, from Eq. 35, in terms of the field at the fluid surface

$$
\varphi=\frac{2 \pi \rho_{f} H_{s}}{\omega} x_{S}(-j) \frac{\frac{d}{d x} b e\left(x_{s}\right)}{b e\left(x_{S}\right)}
$$

Combining Eqs. 85,86 , and 88 produces

$$
i=\frac{\rho_{\mathrm{f}} \mathrm{H}_{\mathrm{s}} l_{\mathrm{t}}}{\rho_{\mathrm{p}}\left(\mathrm{R}+\frac{\mathrm{t}}{2}\right)} \frac{\mathrm{x}_{\mathrm{s}} \frac{\mathrm{d}}{\mathrm{dx}} \mathrm{be}\left(\mathrm{x}_{\mathrm{s}}\right)}{\mathrm{be}\left(\mathrm{x}_{\mathrm{s}}\right)}
$$

or, by Ampere's law,

$$
\left(\mathrm{H}_{\mathrm{p}}-\mathrm{H}_{\mathrm{s}}\right) \ell=\frac{\rho_{\mathrm{f}}}{\rho_{\mathrm{p}}} \frac{\mathrm{H}_{\mathrm{s}} l t}{\mathrm{R}+\frac{\mathrm{t}}{2}} \times \frac{\mathrm{x}_{\mathrm{s}} \frac{\mathrm{d}}{\mathrm{dx}} \mathrm{be}\left(\mathrm{x}_{\mathrm{s}}\right)}{\mathrm{be}\left(\mathrm{x}_{\mathrm{s}}\right)}
$$

where $\mathrm{H}_{\mathrm{p}}$ is the field due to the coil just outside the pipe wall.

From Eq. 90,

$$
\frac{\mathrm{H}_{\mathrm{p}}}{\mathrm{H}_{\mathrm{s}}}=1+\frac{\mathrm{t}}{\mathrm{R}+\frac{\mathrm{t}}{2}} \frac{\rho_{\mathrm{f}}}{\rho_{\mathrm{p}}} \frac{\mathrm{x}_{\mathrm{s}} \frac{\mathrm{d}}{\mathrm{dx}} \mathrm{be}\left(\mathrm{x}_{\mathrm{s}}\right)}{\mathrm{be}\left(\mathrm{x}_{\mathrm{s}}\right)} .
$$

Since the function of $x_{S}$ at the right in Eq. 91 is a complex variable, the field is subject to a phase shift as well as a magnitude change through the pipe thickness.

With currents in both primary (driver) and secondary (generator) coils, the field change applies to both.sets of coils... Thus, by reciprocity, the reduction in signal is the square of the reciprocal of $\mathrm{H}_{\mathrm{p}} / \mathrm{H}_{\mathrm{S}}$ in $\mathrm{Eq} .91$.

In program PIPELOSS (Appendix D),

$$
\text { FUNCR }=\text { real component of } \frac{x_{s} \frac{d}{d x} b e\left(x_{s}\right)}{b e\left(x_{s}\right)}
$$

and

FUNCI = imaginary component of same: 
Values are computed for the same range of $s$ values as in program FLOMGEN. The variables $x_{S}$ and $s$ are related by Eq. 61 .

FUNCR and FUNCI from the computer program along with the pipe dimensions and the resistivities of pipe and fluid in Eq. 91 give the reciprocal of the field attenuation. That is,

$$
\frac{\mathrm{H}_{\mathrm{p}}}{\mathrm{H}_{\mathrm{S}}}=\mathrm{l}+\frac{\mathrm{t}}{\mathrm{R}+\frac{\mathrm{t}}{2}} \frac{\rho_{\mathrm{f}}}{\rho_{\mathrm{p}}}[\text { FUNCR }+\mathrm{j} \text { FUNCI] }
$$

For an example of a pipe-loss calculation, consider sodium at $400^{\circ} \mathrm{C}$ flowing in a stainless steel pipe with an inside diameter of 1.00 in. and a 0.0625 -in. wall. Here, $R=0.500$ in., $t=0.0625$ in., $\rho_{f}=2.19 \times 10^{-7} \mathrm{ohm}$ meter, and $\rho_{p}=7.20 \times 10^{-7}$ ohm-meter.

Take $s=3.17$. Then, from Table II, $f=1094 \mathrm{~Hz}$. From Eq. 61, $\mathrm{x}_{\mathrm{s}}=\sqrt{2 \mathrm{x} .17}=2.52$.

From the output of program PIPELOSS in Appendix D, FUNCR = 1.20, and FUNCI $=1.96$. From Eq. 94,

$$
\begin{aligned}
\frac{\mathrm{H}_{\mathrm{p}}}{\mathrm{H}_{\mathrm{s}}} & =1+\frac{0.0625}{0.500+0.0625} \frac{2.19 \times 10^{-7}}{7.2 \times 10^{-7}}(1.20+\mathrm{j} 1.96) \\
& =1.04+\mathrm{j} 0.0663 \\
& =1.04 \mathrm{cjs} 3.65^{\circ} .
\end{aligned}
$$

Therefore,

$\frac{\mathrm{H}_{\mathrm{s}}}{\mathrm{H}_{\mathrm{p}}}=0.960 \mathrm{cjs}\left(-3.65^{\circ}\right)$

Thus the magnetic field suffers an attenuation of $0.28 \mathrm{~dB}$ and a phase lag of $3: 65^{\circ}$ :

The effect occurs twice for the generated signal. Thus, the pipe causes a loss of $0.56 \mathrm{~dB}$ in magnitude and $7.30^{\circ}$ in phase.

\section{DISC USSION}

In Eq. 60, the.summation term, calculated in programs FLOMGEN and FLOMTEMP, is a dimensionless quantity, which is a function of the variable $s$ and the velocity profile. A particular value of $s$ (approximately 3) yields a maximum value of the function and eliminates its imaginary. 
component. From Eq. 63, the operating frequency must be made to vary inversely with the channel area to hold this fixed value of $s$ in a line of flowmeters of varying sizes.

The actual signal voltage is the product of the dimensionless variable and $K_{n}$, defined by Eq. 59. Equation 60, showing this relation may be written

$$
\mathrm{V}=\mathrm{K}_{\mathrm{n}} \mathrm{V}_{\mathrm{n}}
$$

where $\mathrm{V}_{\mathrm{n}}$ is the normalized voltage calculated in the various computer programs.

Since Eq. 59 contains none of the dimensions of the flowmeter, and since $\mathrm{K}_{\mathrm{ihd}}$ and $\mathrm{K}_{\mathrm{ihg}}$ are dimensionless quantities depending only on the proportions of the coil structure, it is evident that the flowmeter is basically a velocity-sensitive device. Except for the fact that increased primary ampere turns are possible in a larger structure, the signal levels should be the same in large and small flowmeters, if the fluid velocity is the same.

Furthermore, if the frequency is adjusted to provide the desirable value of $\mathrm{s}$, the signal level becomes independent of the fluid resistivity. This leads us to expect that the flowmeter is operable with high-resistivity fluids as well as with the liquid metals. However, the maintenance of balance in the coil system would become increasingly difficult at the higher frequencies, since the false signal due to a residual mutual inductance between primary and secondary coils would be directly proportional to the frequency. This consideration places a practical limit on the fluid resistivity.

The performance tables and curves show about the same change in sensitivity between the lamina - flow condition and marginal turbulence, as over the entire turbulent range, approaching uniform flow. While a calibration factor independent of flow would be possible in the laminar case, the high density and low viscosity of typical liquid-metal coolants would force an extremely low fluid velocity with a resulting low sensitivity and oversize structure.

It is preferable to operate with the fluid in the turbulent state, avoiding the erratic transition to laminar flow by tapering down the flow channel to guarantee a Reynolds number of at least 4000 at the lowest calibrated volume rate. The minimum channel size is limited by the allowable pressure loss in the flowmeter. We have estimated that flow ranges of $60 \mathrm{~dB}$ or greater can be accommodated in liquid sodium with a net pressure loss limited to about 10 psi. 
The spread of the turbulent curves indicates a nonlinear calibration, rather than an error. The effect can be compensated by a nonlinear meter scale or by a corrective nonlinearity in the amplifying equipment.

A gain factor, useful in flowmeter design calculations, can be obtained from Eqs. 59 and 95 by expressing $u_{a}$ in terms of the volume rate and channel diameter, as follows:

$$
u_{a}=\frac{q}{\frac{\pi}{4} D_{C}^{2}}
$$

where $\mathrm{q}$ is the volume rate, and $\mathrm{D}_{\mathrm{c}}$ is the channel diameter. Thus,

$$
\mathrm{G}=\frac{\mathrm{V}}{\mathrm{I}_{\mathrm{d}} \mathrm{q}}=\frac{\mu \mathrm{K}_{\mathrm{ihd}} \mathrm{K}_{\mathrm{ihg}} \mathrm{N}_{\mathrm{d}} \mathrm{N}_{\mathrm{g}} \mathrm{N}_{\mathrm{dg}} \mathrm{V}_{\mathrm{n}}}{\mathrm{D}_{\mathrm{c}}^{\dot{2}}},
$$

where $G$ is the gain factor. Kind is defined by Eq. 45; thus,

$$
\mathrm{K}_{\mathrm{ihd}}=\frac{\mathrm{D}_{\mathrm{c}} \mathrm{H}_{\mathrm{sd}}}{\mathrm{N}_{\mathrm{d}} \mathrm{I}_{\mathrm{d}}} \text {. }
$$

The corresponding relation for $\mathrm{K}_{\mathrm{ihg}}$ is

$$
K_{i h g}=\frac{D_{c} H_{s g}}{N_{g} I_{g}} \text {. }
$$

Note that $\mathrm{H}_{\mathrm{Sd}}$ is the surface field at the generator-driver interfaces, while $\mathrm{H}_{\mathrm{Sg}}$ is the average over the lengths of the generator coils.

The method of Brown and Flax ${ }^{8}$ was used to calculate the field constants for the coil configuration of Fig. 3 (square coil section with inside radius equal to section side).

The average of the values at the four $d-g$ interfaces yields

$$
\mathrm{K}_{\text {ihd }}=0.646 \text {, }
$$

and the average value over the lengths of the two generator double sections is

$$
\mathrm{K}_{\mathrm{ihg}}=1.06
$$

Putting these values, $\mu=4 \pi \times 10^{-7}$, and $V_{n}=0.31$ (a representative peak value for the turbulent curves in Fig. 10) in Eq. 97 gives

$$
G=\frac{V}{I_{d} q}=2.67 \times 10^{-7} \frac{N_{d} N_{g} N_{d g}}{D_{c}^{2}} .
$$


This value may be used for preliminary design calculations, even if the coil proportions deviate appreciably from those of Fig. 3. The 2:67, factor will be increased for more than four $d-g$ coil sections and decreased for two d-g sections, the minimum possible for a balanced system. Even in these cases, the 2.67.factor is probably close enough for preliminary estimates.

The high signal levels provided by the eddy-current flowmeter are demonstrated by estimates on a model for a 15/i6-in. (0.0238-m) channel diameter. This model has $\mathrm{N}_{\mathrm{d}}=\mathrm{N}_{\mathrm{g}}=550$, and $\mathrm{N}_{\mathrm{dg}}=4$. Substituting these values in Eq. 102 gives

$$
\frac{\mathrm{V}}{\mathrm{I}_{\mathrm{d}} \mathrm{q}}=570 \mathrm{~V} / \mathrm{A} /\left(\mathrm{m}^{3} / \mathrm{sec}\right)
$$

or

$$
\frac{\mathrm{V}}{I_{d} \mathrm{q}}=36 \mathrm{mV} / \mathrm{A} / \mathrm{gpm}
$$

A current of 0.35 A causes only a small coil temperature rise and is supplied at a convenient power level. Thus, the sensitivity. of the flowmeter at this nominal current is

$$
\frac{\mathrm{V}}{\mathrm{q}}=12.6 \mathrm{mV} / \mathrm{gpm}
$$

\section{CONC LUSIONS}

1. The eddy-current flowmeter appears well suited to measurements in high-temperature liquid-metal systems since it is not subject to curie-point limitations and temperature and radiation effects on permanent magnets and other ferromagnetic materials.

2. The configuration in which a system of balanced solenoids is wound around the outside of the flow channel is a high-signal-level device.

3. This configuration has an optimum operating frequency (depending on the channel diameter and fluid resistivity) which yields a maximum sensitivity and a signal voltage in phase with the primary current.

4. Temperature errors are minimized if an operating frequency is selected that is the optimum value for the fluid near the midpoint of the expected temperature range. Alternatively, a simple temperature compensation system is to allow the frequency to follow the fluid resistivity changes by adjusting for zero phase angle in the signal. 
5. Operating frequencies much in excess of the optimum value produce an extreme sensitivity to fluid layers near the boundary surface and therefore create sensitivity uncertainties due to velocity-profile changes.

6. The optimum operating frequency for large-diameter channels becomes very low. If high speed of response is required in the flowmeter, the requirement for low. frequency may limit the range of application of the external coil system to the smaller channel diameters. 


\section{APPENDIX A}

\section{Program SIGPROF}

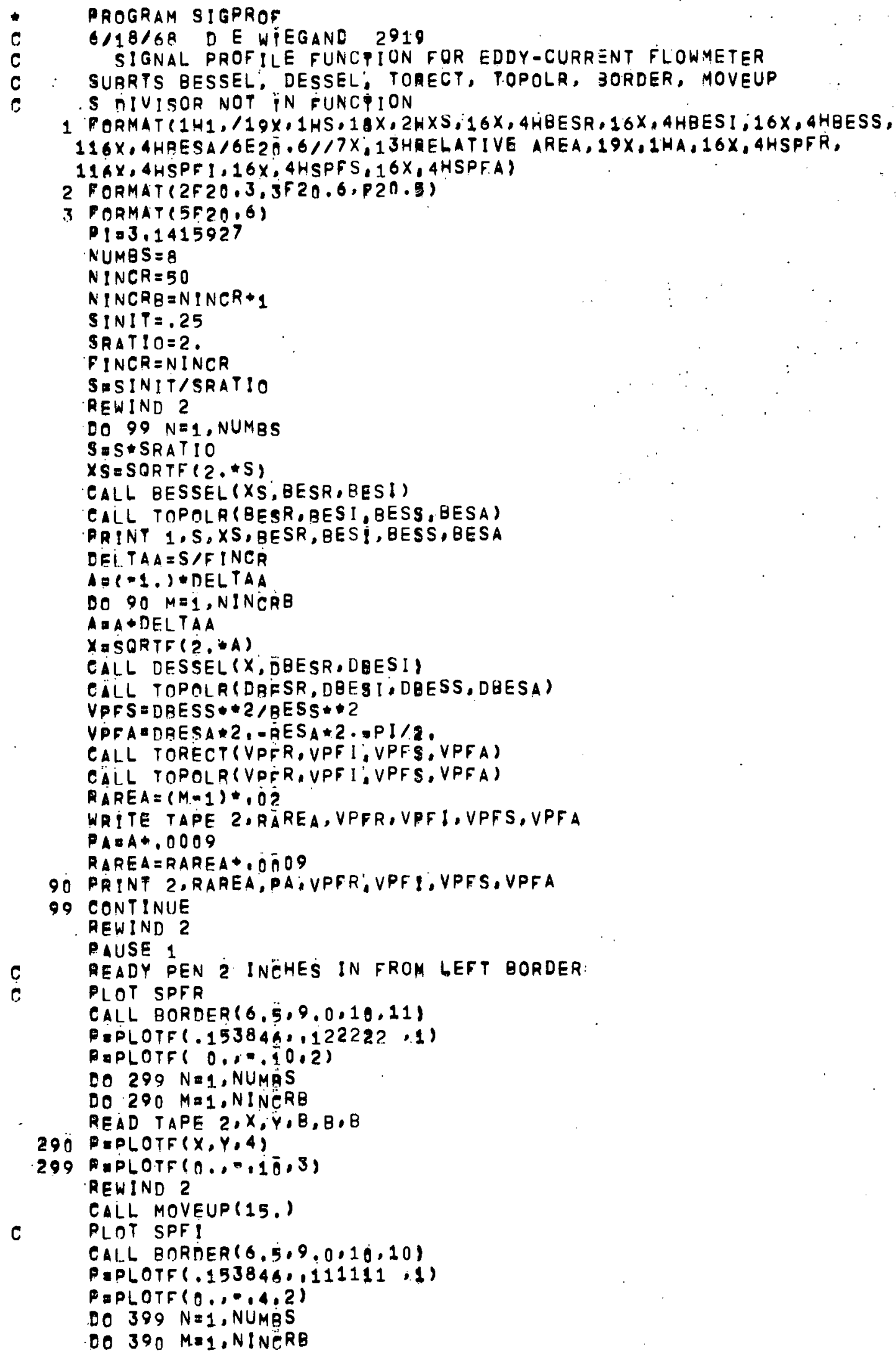


READ TAPE $2, X, B, Y, B, B$

$390^{\circ}$ PQPLOTF( $\left.X, Y, 4\right)$

J99:P PLOTF $(0, .0 .4,3)$

GEWIND 2

CALL MOVEUP(15.)

c.

Plot SPFS

CALL BORDER $(0.5,9.0 .10 .10)$

ontotr .1538460 .111111 .1$)$

PaPLOTF $(0,0,0,2)$

DO $499 \quad N=1$, NUMBS

DO $490 \quad M=1$, NINERB

READ TAPE $2, X, R, B, Y, B$

490 PDLOTF $(X, Y, 4)$

499 PaPLOTF $(0, .0,3)$

REWIND 2

c.

CALL MOVEup(15.)

Plot SPFa

CALL BORDER $(6,5 \cdot 9.0 .10,14)$

PELOTF(.153846..777798.1)

DiPLOTF(0..-3.5.2)

NINCRL $\equiv N$ INCR-I

Dก $599 \quad N=1$, NUMBS

READ TAPEZ,B,B,B,B,B

READ TAPE $2, X, B, B, B, Y$

A.PLOTF $(X, Y, 3)$

DO $590 \quad N=1, N I N E R L$

READ TAPE $2, X, B, B, B, Y$

590 DPLOTF $(X, Y, 4)$

599 PIPLOTF $(0 .,-3.5,3)$

REWIND 2

CALL MOVEUP(15.)

REWIND 2

END 
APPENDIX B

\section{Program F LOMGEN}

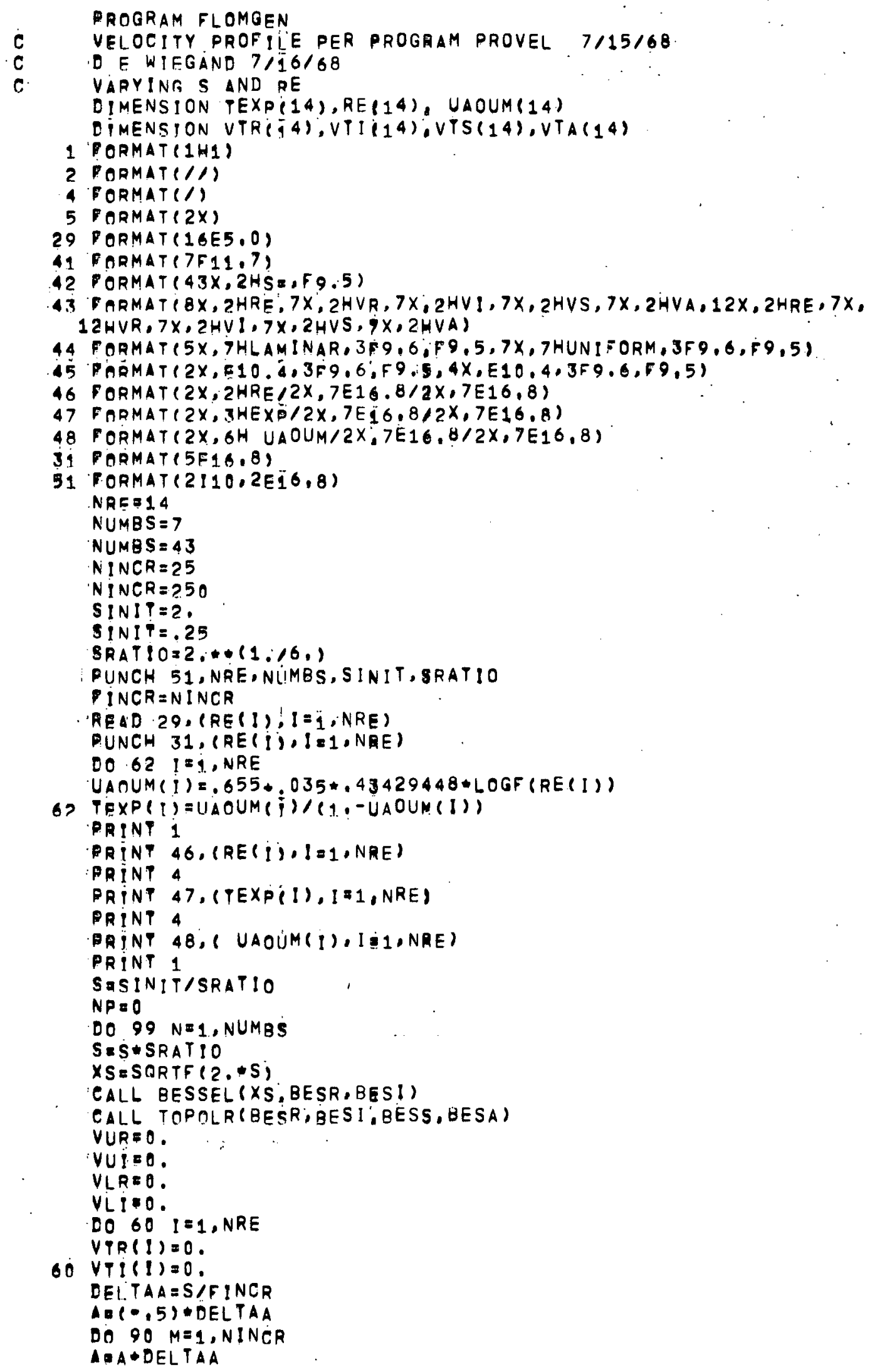


$X=\operatorname{SORTF}(2, * A)$

CALL DESSEL ( $X$, DDBESR, PDBESI)

TUNCR $=2 . P D B E S R * P D B E S$ I

FUNCI =PDRES I**j-PDBESR *2

VUR $=$ VUR +FUNCR

$V U !=V U I+F U N C !$

$\operatorname{LOS}=X *+2 / 2,15$

UL. OUUA $=? \cdot *(1,-A O S)$

$V L R=V L R+F U N C R+U L O U A$

$V L I=V L I+F U N C I+U L O U A$

DO $631: 1, N R E$

UTOUAE $(1 .-A O S$ TEXP(I) IUAOUM(I)

VTR ( I) =VTR(!) +FUNCR U UOUA

$V P I(I)=V P I(I)+F U N C I$ UPOUA

63 CONTINUE

OD CONTINUE

EALL TOPOLR (VUR, VUI, VUS, VUA)

EALL TOPOLR (VLA.VLI, VLS,VLA)

DO $65 \quad 1=1$, NRE

PVTREVTR(I)

DVTIEVTI(I)

CALL TOPOLR (PVYR, PVTI, PVTS,PVTA)

VTS $(1)=$ PVTS

$65 V T A(1)=P V T A$

CORREFINCR*BESS**2

CORA $=B E S A+2$,

VUS $=$ VUS/CORR

VLSEVLS/EORR

VUA $: V U A=C O R A$

$V L A \equiv V L A-C O R A$

$0067 \quad I=1, N R E$

VTS(l)=VTS(I)/COORR

67 VTA $(1)=V T A(I)-C O R A$

CALL TORECT (VUR, VUI, VUS, VUA)

CALL TORECT (VLR, VLI, VLS,VLA)

CALL TOPOLR (VUR, VUI, VUS, VUA)

CALL TOPOLRSVLR,VLI, VLS, VLA)

DO $69 \quad I=\dot{I}, N R E$

CALL TORECT(VTR(I),VTI(I), VTS(I),VTA(I))

69 CAIL TOPOLACVTR(I),VTI(I),VTS(I),VTAPI)

IF $(N P-3) 71,71,70$

TO RRINT 1

$N P=0$

91 CONTINUE

ORINT 2

$S=5+1,00000002$

PRINT 42,5

PRTNT. 43

PRINT 5

DRINT 44, VLR, VLI, VLS, VLA, VUR, VUI, VUS, VUA

FUNCH 31. VLR, VLI, VUR, VUI

PRINT 45 ; (RE(I),VTR(I),VTI(I),VTS(I),VTA(I), I=1,NRE)

PUNCH 31, (VPR(I), VTI(I),IE1,NRE)

$N P=N P+1$

99 'CONT INUE

END

$.4 E 4.1 E 5$.2E5 . 4E5 .1E6 .2E6 .4E6 .1E7 .2E7 .4E7 .1E8,.2E8 .4E8 .1E9 
RE

LAMINAR $.4000 E 04$ $.2000 E 05$ .1000 U6 $.4000 E 06$ $.2000 E \quad 07$ $.1000 E 08$ $.4000 E 08$

\begin{abstract}
VR
\end{abstract}
.007688 .009055 .009188 .009323 .009441 .009578 .009716 .009834

\begin{abstract}
V I
\end{abstract}
.040622 .050070 .051105 .052185 . 053152 .054321 055544 .056642
vs

.041545 .050882 .051925 .003011 .033984 .055160 .056387 .057489

$S=$
$V A$
$1: 38373$
$1: 39187$
$1 ! 39239$
$1: 39399$
$1 ! 39500$
$1: 39625$
$1: 39752$
$1: 39888$

VI

vs

009647 .009647 .011363 .011700 .011848 .012020 .012193 .012342
.045297 .052856 .057014 .058221 .059303 .060612 .061980 .063209
.046515 .057000 .058168 .059385 .000475 .061792 .063168 .064403
$S=$

VA .28061

1.36084 1. 37009 $1: 37123$ $1: 37246$ 1.37359 1.37501 1.37653 1.37775

$$
\text { RE }
$$

VR

UNIFURM $.1000 E 05$ . $4000 E 05$ $.2000 E 06$ $.1000 E 07$ $.4000 E 07$ $.2000 E 08$ $.1000 E 09$
.010263 .009131 .009246 .009382 .009519 .009637 .009775 .009912
VI

.061173 .050654 .051565 .052664 .053812 .054841 .056087 .057392 vs

.062028 .051471 .052387 .053493 .054647 .055682 .056933

.058242
VA

1.40456 1.39 .244 i. 39335 1.39448 1.39570 1.39083 1.39824 1.39977

$.1000 E 0$ .4000 O8

RE

VR

VI

vs

$S=$
$V_{A}$
1.33542
1.34569
1.34677
1.34835
1.34962
1.35121
1.35272
1.35451

.31498

RE

VR

V I

vS

VA

UNIFORM $\quad .012882 \quad .068284$ $.1000 E 05 \quad .011458$ $.4000 E \quad 05 \quad .011604$ $.2000 E$ O6..011774 $.1000 E 07 \quad .011946$ $.4000 E \quad 07 \quad .012095$ $.2000 E 08 \quad .012266$ $.1000 E$ OQ .012440

.056509 .057528 .058757

.060041 .061193 .062588 .064049

.069488 .057650 .058686 .059925

.061218 .062577 .063779

.065246

1.38433 2.37073 1.31175 1.37302 1.37439 1. 3/565 1. 37723 1.37895

LAMINAR .012092 .050424 .021853 .063820 .065129 .014455 .063504 .066492 .067713 .069188 -1160063 .061526 .069056 .010728 .0721111 .35451

UNIFURM $.1000 E 05$ $.4000 E 05$ $.2000 E .06$ $.1000 E 07$ $4000 E 07$ . $2000 E 08$ $.1000 E 09$

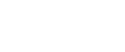

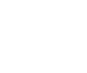


RE

LAMINAR .015136 $.4000 E 04.017835$ $.2000 E 05 \quad .016099$ $.1000 E 06.018366$ $.4000 E 06.018598$ $.2000 E 07.018870$ $.1000 E 08 \quad .019142$ $.4000 E 08 \quad .019377$
V I

.056009 .069148 .070593 .072099 .073450 .075084 .076793 .078329.

$$
\text { vS }
$$

.028018 .011411 .072876 .074402 .075768 .017419 .079143 .080691

$S=$
$V A$
1.30635
1.31837
1.31931
1.32136
1.32279
1.32457
1.32649
1.32828

.35355

(

RE

UNIFORM .1000E OS $.4000 E \quad 05$ $.2000 E 06$. .1DOOE U7 $.4000 E \quad 07$ $.2000 E 08$ $\because 1000 E 09$
VR

.020228 .017984 .018213 .018482

.018753

.018987

.019260

.019531
VI

.084682 .069963 .071234 .072768 .074371 .075810 .077553 .079380 vs

VA

.087065 .072238 073525 .075078 .076698 .078152 .079909 081747
1.35631 1. 31918 1.32047 1.32206 1.32379 1.32538 1.32737 1.32953
RE

VR

.018915 .022293 .022623 .022958

023249 .023590 .023932 .024225
VI

vS

$S=$

VA .39685

.062045 .076666 .078275 .079954 .081460 .083283 .085190 .086906
.004864 .079841 .061479 .083185 .084713 .060560 .088488 .070219
1.27438 1.28781 1.28943 1.29117 1.29277 1.29477 1.29693 1.29873
RE

VR

UN IFORM $.1000 E \quad 05$ $.4000 E \quad 05$ $.2000 E 06$ $.1000 E 07$ $.4000 E \quad 07$ $2000 E 08$

$.1000 E 09$
.025293 .022480 .022767 .023104

.023443

023737 .024079

.024419
V I

.094005 .077574 .078989 .080700 .082488 .084094 .086039 .088079 vs

VA

$.097348 \quad 1.30795$

.0807051 .28872

$.0822051 .2 \overline{9} 016$

.0839421 .29196

.0857551 .29389

$.087360 \quad 1.29568$

.0893451 .29791

$.091401 \quad 1.30034$
RE

VR

LAMINAR $.4000 E 04$ .2000505 $.1000 E 06$ $.4000 E 06$ $.2000 E 07$ $.1000 E 08$ $.4000 E 08$
V I

vs

023587 .027809 .028223 .028642 .029006 .029432 .029860 .030228
495 . 084729 .086519 .088388 .0 .90065 .092095 .094220 .096132

\section{$S=\quad .44545$}

VA

RE

VR

V!

vs

VA

$07.2445 \quad 1.23914$ $089176 \quad 1.25365$ $091006 \quad 1.25547$ , 0929131.25742 $.044620 \quad 1.25922$ $.046683 \quad 1.26146$ . $098838 \quad 1.26399$ .1007731 .26614
UNIFORM .031566 $.1000 E 05 \quad .028044$ $.4000 E$ O5 .028402 $.2000 E 06.028823$ $.1000 E \quad 07 \quad .029248$ $.4000 E 07.029616$ $.2000 E$ OB .030044 $.1000 E 09.030470$
.104056 .085739 .087314 .089218 .091209 .092998 .095166 .097441
$.108739 \quad 1.27626$ .0902091 .25467 $.091818 \quad 1.25629$ .0937591 .25831 .0957841 .26048 $.097600 \quad 1.26248$ $.099796 \quad 1.26499$ $.102094 \quad 1.26772$ 


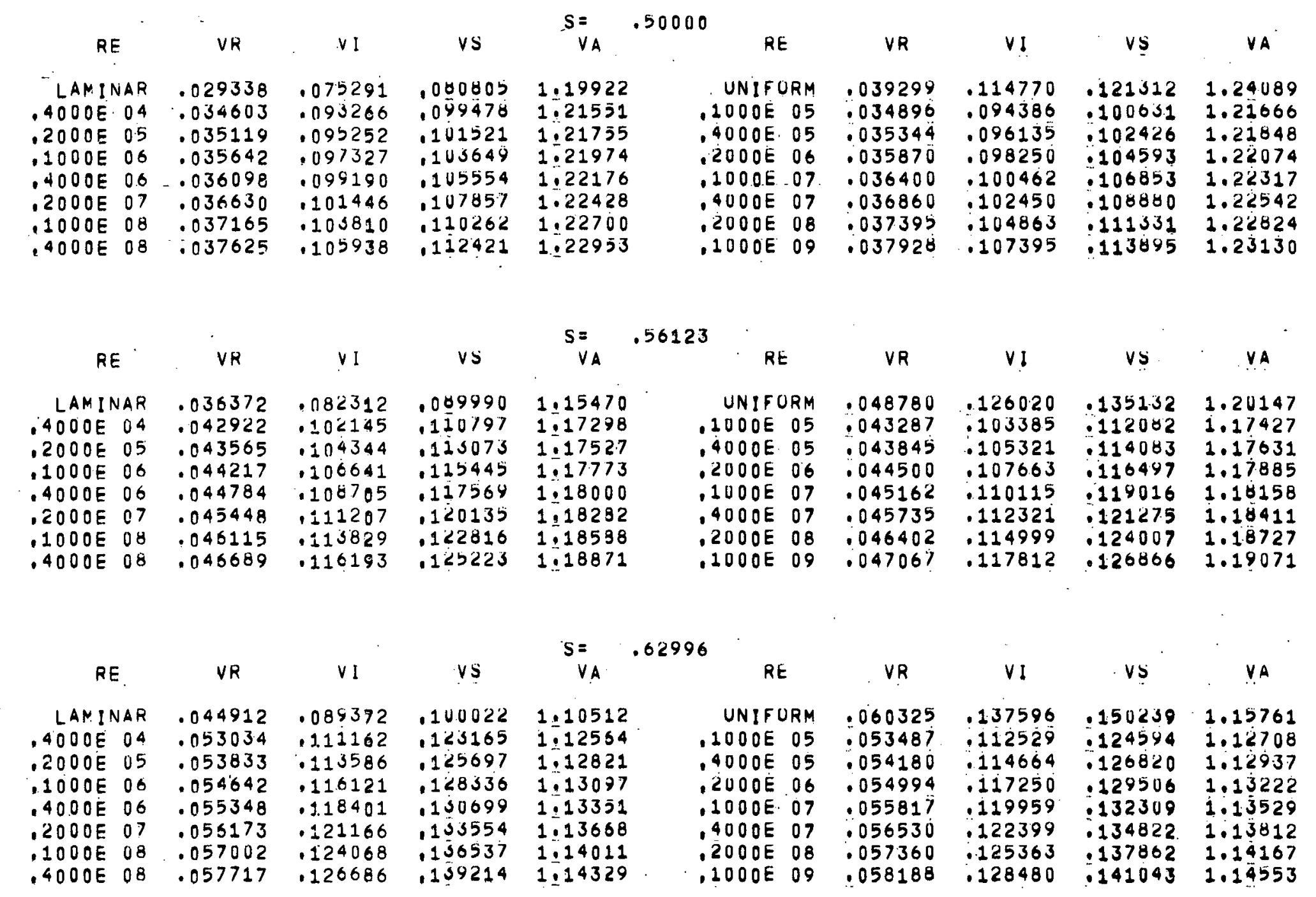




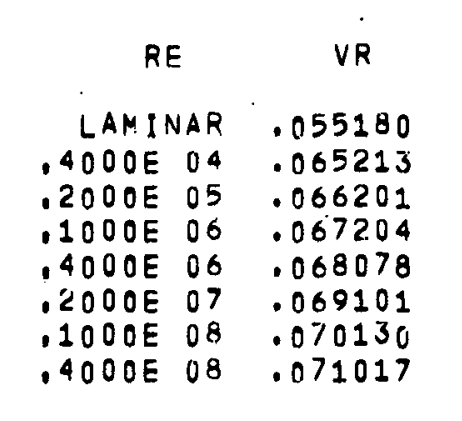

$$
\text { VI }
$$

.096200 .120012 .122673 .125460 . 1.27967 .131012 .134212 . 1.37101$$
\text { vs }
$$

$$
V_{\text {A }}=.70710
$$

$110902 \quad 1.05001$

11.07304

$1359396 \quad 1.07572$

$112325 \quad 1.07902$

$1 \overline{44949} 1.08138$

1481191.08543

$.151430 \quad 1.08928$

$.194403 \quad 1.09236$
RE

UN IF ORM

$.1000 E 05$

. $4000 E 05$

$.2000 E 06$

$.1000 E 07$

$.4000 E 07$

.2000E 08

$.1000 E 09$
VR

.074259 .065774

.066631

.067640

.068659

069544

.070574

.071602
V!

VS

VA

.149182. 121512 .123857 .129682 132370 .135641

.139084

.160642 .138172 .140643 .143625 .146737 .149527 .152902 .156433
VI

.160327 160327
129908 129908
$: 132471$ .135581 .138847 .138847 .145388 .149177 vs

.184301 .152778 .155514 .158816 .162261 .165350 .169088 .172997
1.10893

1.07466 i. 07723 1.08043 1.08387 1.08705 1.09104 1.09537

$V A$
03503
01656
01945
02304
02690
03048
03495
03981

RE

VR

VI

vs

LAMINAR .2000 05 .098227 $.1000 E 06$ $.4000 E 06$ $.2000 E 07$ $.1000 E 08$ $.4000 E 08$
.099744 .101068 .102621 .104185 .105535
.107542 .1 .35372 .138524 .141833 .144820 .148457 .152293 .155769
105032 .166382 .104816 .173395 .176000 .160473 .184520 . 1 ธิ8153

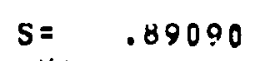

VA

.92134 .95035 .95398 .95789

.96148 .96596

.97081 .97532 $.4000 E 05$ $.2000 E 06$ $.1000 E 07$
$.4000 E 07$ . 200OE 08 $.1000 E 09$

(2)




RE
LAMINAR
$.4000 E$ O4
$.2000 E$ OS
$.1000 E$ O6
$.4000 E$ O6
$.2000 E$ OO
$.1000 E$ OB
$.4000 E$ OS

VR

$V I$
110937

$\begin{array}{ll}.098002 & .110937 \\ .116354 & .140600 \\ .118173 & .143990\end{array}$

.118173

.120024

.150784

123536,154721

.125450 .158882

.127104 vs

.148065

1102501

.106275

1190208

.193732

.147989

.202438

.206432

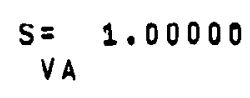

VA

.84692

.87947

.88355

88773

.89197

.89700

.90244

$\therefore 90749$

\begin{tabular}{|c|c|}
\hline RE & VR \\
\hline UNIFORM & .133198 \\
\hline 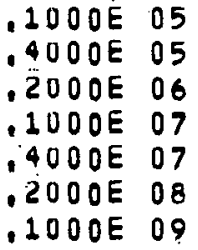 & $\begin{array}{l}.117386 \\
.118967 \\
.120829 \\
.122717 \\
.124359 \\
.126276 \\
.128197\end{array}$ \\
\hline
\end{tabular}

V!

.178689

.142509

.145504

.149152

.152 .999

.156484

.160748

.165267

\begin{abstract}
vs
\end{abstract}
.222872

.184631

.187949

.191954

.196133

.199881

.204416

.209100
VA

.93023

80176

$.8 \overline{540}$

.88992

.89478

.84929

.90492

.91104
RE

LAMINAR $.4000 E 04$ $.2000 E 05$ $.1000 E 06$ .4000 E. 06 $.2000 E 07$

$.1000 E 08$

$.4000 E 08$

$$
\text { VR }
$$

.116458 .138469 .140669 .142909 .144867 .147169 .149494 .151507

\section{VI}

.111866 .143095 .146707 .150516 .153970 .158196 .162676 .166756

\begin{abstract}
$S=$
VA

.76529

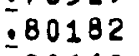

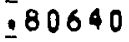

.81131

81534

.82149

.82759

.83327
\end{abstract}

.161482

1199123

.203250

.207553

.211408

.216066

.220934

.245305

2246
$.1000 E 05$ $.4000 E 05$ $.2000 E .06$ $.1000 E 07$ $.4000 E 07$ $2000 E 08$ $.1000 E 09$
VR

.158953 .139717 .141629 .143885 .146174 .148168. .150500 .152839
V!

.184184 .145128 .148322 .152222

.156346 .160093 .164689 .169575

$\begin{array}{cc}\text { VS } & \text { VA } \\ 243240 & .85879 \\ 201452 & .80439 \\ 205081 & .80847 \\ 209463 & .81354 \\ 214035 & .81900 \\ 218136 & .82406 \\ 223098 & .83038 \\ 228289 & .83725\end{array}$

$S=1.25992$

VA

'RE

VR

VI

vํํ

VA.:

.67621

.71721

.72235

.72736

.73295

.73928

.74613

.75250
UNIFORM $.1000 E 05$ $.4000 E 05$ $.2000 E 06$ .1000E 07

$.4000 E^{\circ} 07$

$.2000 E 08$ $1000 E 09$
.187420

.164196

.166490

.169198

.171952

.174353

.177167

.179996
.185840

.144038

.147406

.151531

.155906

.159895

.164806

.170046

$\begin{array}{ll}.263937 & .78116 \\ .218420 & .72009 \\ .222368 & .72467 \\ .227134 & .75036 \\ .232108 & .73649 \\ .236570 & .74216 \\ .241969 & .74926 \\ .247618 & .75698\end{array}$


RE

VH

- VI

LAMINAR $.4000 E 04$ $.2000 E$ O5 $.1000 E 06$ $.4000 E 06$ $.2000 E \quad 07$ $.1000 E$ OB $.4000 E 08$

.157444 .188320 .191447 .194641 .197441 .200743. .204092 .207004

.103065 .136045 .139991 .144183 . .148010 .152727 .157768 .162396
RE

UNIFORM 252321 .257170 .242227 246759 .252237 , 237962 .203104
.57961 .62561 $\lcm{63137}$ .63756 .64327 .65038 .65807 .66522
$1000 E \quad 05$ $.4000 E .05$ $.2000 E 06$ $.1000 E 07$ 4000E 07 $.2000 E 08$ , $1000 E 09$
VR

217884 190092 .192815 .196035 . 199315 .202181 .205546 .208937
V!

.182552 .138263 .141765 .146070 .150657 .154856 .160047 .165614 vs VA

.284251 .235057 239322 .244472 .249848 .254671 .260508 .266614

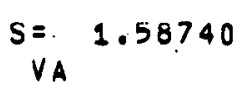

VA

RE

VR

VI

vs

VA

.47558

.52719

. 53366

.54050

.54700

.55498

56351

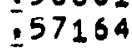

UN IFORM $.1000 E 05$ $4000 E$. 05 $.2000 E 06$ $.1000 E 07$ $.4000 E \quad 07$ $.2000 E 08$ $.1000 E 09$

.249183 .216263 .219457 .223242 .227106 .230490

.234473

.238499

$\begin{array}{lll}.173332 & .303540 & .60776 \\ .126951 & .250771 & .53082 \\ .130534 & .255344 & .53659 \\ .134960 & .260867 & .54375 \\ .139701 & .266634 & .55147 \\ .144062 & .271808 & .55861 \\ .149484 & .278070 & .56755 \\ .155331 & .284622 & .57727\end{array}$

RE

UNIFURM .1000E OS $.4000 E 05$ $.2000 E 06$ $1000 E \quad 07$ $.4000 E 07$ $.2000 E 08$

$.1000 E 09$
VR

VI

v

VA

.36447

.42237

42932

.43741

.44450

.45355

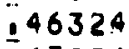

.47224
$.279715 \quad .157494$. .241163 .109565 .244860 .113163 249253 $.253748 \quad .122453$ $.257690^{\circ} .126916$ .262356 .132498 $.267083 \quad .138563$
$.321006 \quad .51281$

$264885 \quad .42644$

$.269745 \quad .43291$

$.275617 \quad .44095$

.281750 .44961

$.287234 \quad .45763$

$.293916 \quad .46766$

.300887 .047857
.69739 .62884 .63398 .64037 .65361 .66158 .67024

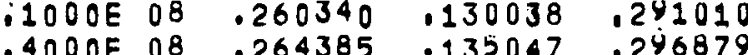




\begin{tabular}{|c|c|c|c|c|c|c|c|c|c|}
\hline RE & VR & VI & vs & $\begin{array}{l}S= \\
V_{A}\end{array}$ & 2.00000 & VR & VI & vṣ & VA \\
\hline 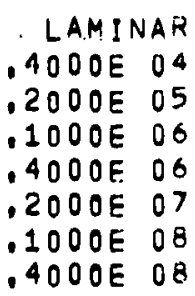 & $\begin{array}{l}.214030 \\
.260208 \\
.265037 \\
.270004 \\
.274391 \\
.279605 \\
.284941 \\
.289622\end{array}$ & $\begin{array}{l}.053944 \\
.083897 \\
.087822 \\
.092094 \\
.096066 \\
.1 .01055 \\
.106500 \\
.111599\end{array}$ & $\begin{array}{l}.220724 \\
.273593 \\
.279208 \\
.285278 \\
.290722 \\
.297307 \\
.304193 \\
.310380\end{array}$ & $\begin{array}{l}: 24639 \\
: 31133 \\
: 31977 \\
332871 \\
: 33677 \\
: 34689 \\
: 35768 \\
: 36779\end{array}$ & 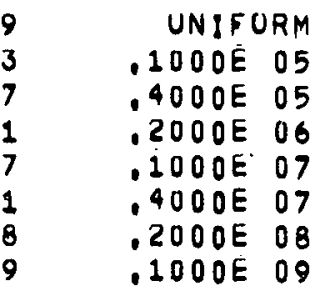 & $\begin{array}{l}.307521 \\
.262940 \\
.267159 \\
.272185 \\
.277344 \\
.281889 \\
.287273 \\
.292753\end{array}$ & $\begin{array}{l}.134881 \\
.086085 \\
.089620 \\
.094044 \\
.098854 \\
.103341 \\
.108999 \\
.115199\end{array}$ & $\begin{array}{l}.335801 \\
.276674 \\
.281790 \\
.287974 \\
.294435 \\
.300255 \\
.307256 \\
.314604\end{array}$ & $\begin{array}{r}.41334 \\
.31639 \\
.32365 \\
.33267 \\
.34239 \\
.35138 \\
.36264 \\
.37489\end{array}$ \\
\hline RE & VR & VI & Vs & $\begin{array}{c}S=2 \\
V_{A} .\end{array}$ & 2.24492 & VR & VI & V $\underline{s}$ & YA \\
\hline 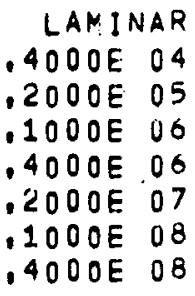 & $\begin{array}{l}.225558 \\
.276587 \\
.282003 \\
.287592 \\
.292544 \\
.298451 \\
.304519 \\
.309865\end{array}$ & $\begin{array}{l}.028052 \\
.055072 \\
.058832 \\
.062946 \\
.066806 \\
.071702 \\
.077100 \\
.082205\end{array}$ & $\begin{array}{r}.227290 \\
.282017 \\
.288074 \\
.294400 \\
.300075 \\
.306943 \\
.314128 \\
.320584\end{array}$ & 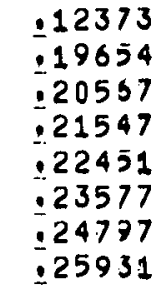 & 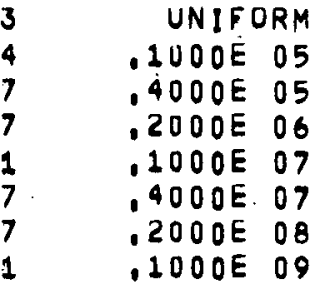 & $\begin{array}{l}.330507 \\
.279649 \\
.284388 \\
.290052 \\
.295887 \\
.301045 \\
.307179 \\
.313452\end{array}$ & $\begin{array}{l}.106041 \\
.057172 \\
.060558 \\
.064837 \\
.069536 \\
.073961 \\
.079596 \\
.085836\end{array}$ & $\begin{array}{l}.347102 \\
.285434 \\
.290705 \\
.297210 \\
.303948 \\
.309998 \\
.317324 \\
.324992\end{array}$ & $\begin{array}{r}.31046 \\
.20166 \\
.20980 \\
.21992 \\
.23082 \\
.24091 \\
.25354 \\
.26729\end{array}$ \\
\hline & & & & & & & & & \\
\hline RE & VR. & VI & VS & $\begin{array}{c}S= \\
V_{A}\end{array}$ & 2.51984 & VR & VI & vs & VA \\
\hline $\begin{array}{l}\text { LAMINAR } \\
14000 E \text { O } \\
12000 E \text { O5 } \\
11000 E \text { O } \\
14000 E \text { OS } \\
12000 E \text { O } \\
11000 E \text { OB } \\
4000 E \text { OB }\end{array}$ & $\begin{array}{r}.230843 \\
.286175 \\
.292149 \\
.298338 \\
.303842 \\
.310433 \\
.317234 \\
.323253\end{array}$ & $\begin{array}{r}.000893 \\
.026295 \\
.025771 \\
.029624 \\
.033284 \\
: 037981 \\
.043226 \\
.048244\end{array}$ & $\begin{array}{r}.250844 \\
.287042 \\
.293284 \\
.299805 \\
.305659 \\
.312748 \\
.320166 \\
.326833\end{array}$ & $\begin{array}{r}-0.0336 \\
\div 07775 \\
\div 08798 \\
\div 09877 \\
\div 10910 \\
\div 12174 \\
\div 13542 \\
.14815\end{array}$ & 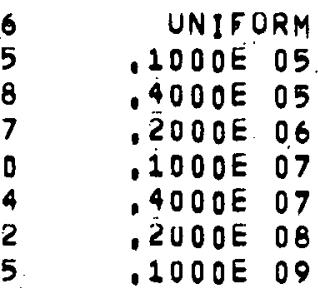 & $\begin{array}{r}.346750 \\
.289550 \\
.294780 \\
.301070 \\
.307568 \\
.313337 \\
.320226 \\
.327305\end{array}$ & $\begin{array}{l}.072311 \\
.024231 \\
.027382 \\
.031412 \\
.035895 \\
.040168 \\
.045673 \\
.051846\end{array}$ & $\begin{array}{r}354210 \\
.290562 \\
.29 .6057 \\
.302704 \\
.309655 \\
.315901 \\
.323466 \\
.331386\end{array}$ & $\begin{array}{l}.20559 \\
.08349 \\
.09262 \\
.10396 \\
.11618 \\
.12750 \\
.14167 \\
.15709\end{array}$ \\
\hline
\end{tabular}


RE

VR

VI

vs

$.028932=.030984$

$.287786 \cdot .012403$

$.294267 \ldots .009303$

$.301008 \cdot .005807$

$.307029 \cdot .002434$

.314270 .001959

.321781 .006944

$.328459 \quad .011781$
.201019 .288053 $12 \overline{4} 4414$ .301064 .307038 .314276 , $3<1856$ $3 \div 8671$

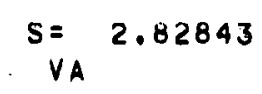

\section{RE}

LAMINAR $.4000 E 04$ $.2000 E \quad 05$ .1000 06 $.4000 E 06$ $.2000 E 07$ $.1000 E 08$ $.4000 E 08$

$$
\text { VR }
$$

VI

$.219625 \cdot .060002$ $.281042-.046591$ $.287956 \cdot .043945$ $.295182 \cdot .040800$ $.301665-.037882$ $.309501-.033886$ $.317673 \cdot .029262$ $.324978 \cdot .024695$
VS

.267674 .264878 .241290 .298001 .344035 . 311351 .329018 .325915

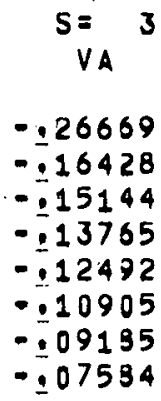

$$
\text { RE }
$$

VR

VI

vs

VA

UNIFURM $.1000 E$ OS $.4000 E 05$ $.2000 E 06$ $.1000 E 07$ $.4000 E 07$ $.2000 E 08$ $.1000 E 09$

$.354850 \quad .035732$ $.291444 \cdot 010683$ .297137 .007849 .303993 .004165 $.311118 \cdot .000000$ .317472 .004028 $.325096 \quad .009295$ .332975 .015291
.356044

.291640

297241

304022

.311118

317498

.325220

$.33332 \%$
.10035

. .03664

$\therefore 02640$

$-.01370$

.00000

.01268

.02858

.04589

VA

UNIFURM $.1000 E 05$ $.4000 E .05$ $.2000 E 06$ $.1000 E 07$ $.4000 E 07$ $.2000 E 08$ . $1000 E$ OQ

VR

VI

VS

$.354220 \cdot 0.001210$ $.284941-0.045131$ $.291029 \cdot .042683$ $.298393 \cdot 039433$ $.306086 \cdot .035678$ $.312979 \cdot 0.031977$ $.321295 \cdot .027051$ $.329938 \cdot .021338$

.354223 .288493 .294142 300988 .308158 .314609 322432 .330628

.00341 . .15708 . .14562

. .13139

. .11604

$-.10181$

. .08398

$-.06458$

\section{$S=\quad 3.56359$}

VA

RE

VR

V!

VS

VA

$.2<0886-.39873$

$.217619 \quad-.28415$

$.284019 \quad-.26978$

$.290726 \quad-.25434$

$.296762=.24010$

$.304089 \quad-.22232$

$.311775-.20306$

$.318694-.18512$

UNIFORM .345227.0.035971 $.1000 E$ O5 ..270576..076662 .4000 05 ..276984 -..074655 .2000 06 .284774=.071908 $.1000 E 07.292956 \cdot .068641$ $.4000 E 07 \quad .300328-.065340$ $.2000 E 08 \quad .309271 \cdot .060846$ $.1000 E 09.318624 \cdot .055513$

$\begin{array}{ll}.347096 & -.10382 \\ .281226 & -.27609 \\ .286869 & -.26327 \\ .293713 & -.24733 \\ .300890 & -.23015 \\ .307354 & -.21422 \\ .315199 & -.19425 \\ .323424 & -.17249\end{array}$




\section{$.210954 \quad-.52896$} $.206047 \quad-.40091$ $.272980 \quad-.38435$ $.279625 \quad-36750$ $.285616 \quad-.35157$ $.292896-.33179$ $.300543-.31023$ $.307435=.29014$ $.1000 E 05$ $.4000 E 05$ $.2000 E 06$ $.1000 E$ OT $.4000 E 07$ $.2000 E 08$ $.1000 E 09$

$.329118 \cdot .066350$ $.249728-.103210$ $.256375 \cdot .101680$ $.264497-.099487$ $.273078-0.096766$ $.280854 \cdots .093923$ $.290343-.089934$ $.300334 \cdot .085064$

$\begin{array}{ll}.335740 & -.19893 \\ .270215 & -.39191 \\ .275802 & -.37757 \\ .282589 & -.35976 \\ .289716 & -.34054 \\ .296143 & -.32272 \\ .303953 & -.30038 \\ .312149 & -.27600\end{array}$

RE

LANINAR $.4000 F 04$ $.2000 E 05$ $.1000 E 06$ $.4000 E 06$ $.2000 E \quad 07$ $.1000 E .08$ $.4000 E 08$

$$
\text { VR }
$$

VS

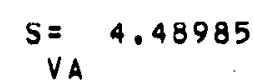

RE

VR

VI

UN I FORM

$.157224 \cdot .120944$ $.220059-.123920$ $.227720 \cdot .122912$ $.235859=.121501$ $.243281=.119900$ $.252401=.117506$ $.262093=.114420$ $.270916 \cdot .111095$
1198360

$.252552-.51286$

$238774 \quad-.49474$

$205316-.47558$

$.271222 \quad . .45770$

$.278414 \quad . .43571$

285980.41162

$.292810 \quad .38916$
$.1000 E 05$ $.4000 E 05$ $.2000 E 06$ $.1000 E 07$ $.4000 E 07$ .2000 OB $.1000 E 09$
$.307777 \quad .0090815$ $.224364-.123392$ $.23116 \overline{5}-.122359$ $.239521-.120749$ $.248405-.118614$ $.256504 \cdot .116270$ $.266449-.112842$ $.276993-.108500$

\section{vs}

.320896 .256056 .261551 .268237 .275271 .281625 .289359 .297485
VA

. .28692

$-.50281$

$-.48682$

. .46694

$-.44548$

$\therefore .42558$

. .40060

. .37333
RE

VR

VI

vs

$S=$
$V A$

RE

VR

VI

vs

VA

$.103712 \cdot .77730$

$.236073 \quad . .61835$

$.242156 \quad-.59841$

$.248566-.57697$

$.254367 \quad-.55718$

$.201445-.53245$

$.268909 \quad . .50559$

$\begin{array}{ll}1208909 & .50559 \\ .275660 & .48053\end{array}$
UNIFORM .1UOOE 05 $.4000 E 05$ $.2000 E 06$ $.1000 E 07$ $.4000 E \quad 07$ . $2000 E 08$ $.1000 E 09$
$.283372 \cdot 108650$ $.196690 \therefore 136644$ $.203562-.136111$ $.212055 \cdot .135097$ $.221144-.133568$ $.229482-.131747$ $.239788=.128919$ $.250794 \cdot .125151$
$.303488 \quad 0.36613$ $\begin{array}{ll}.239497 & -.60717\end{array}$ $.244875 \quad-.58937$ $.251433 \quad-.56724$ $.258350 \quad-.54334$ $.264611 \quad-.52116$ $.272247-.49330$ $.280287-.46286$ 
RE

VR

VI

vS

$V_{\text {A }}=5.65686$

$.105266 \cdot .130521$ $.164506=.143078$ $.172189 \cdot .143199$ $.160458 \cdot .142958$ $.188090=.142393$ $.197589 \cdot .141222$ $.207827 \cdot .139363$ $.217275 \cdot .137075$
.107681
.218022
.223953
.230222
.255910
.242869
.250228
.256901
$-.89209$

$-.71594$

. .69373

. .66976

. .64799

$-.62054$

. .59070

. .56282
RE

VR

VI

VS

VA

UNIFORM . $1000 E 05$ $.4000 E \quad 05$ $.2000 E \cdot 06$ $.1000 E 07$ $.4000 E \cdot 07$ $.2000 E .08$ $.1000 E 09$
$.258007-.119933$ .168811 .143186 $.175676-.143144$ .1842120 .142722 $.193410 \cdot .14180$ $.201905 \cdot .140515$ $.212476=138308$ .223852 .1135143
.284520

.221359

.226610

.233032

.239424

.245988

.253526

.261483
. .43513 . .70344 $-.68371$ . .65916

.063263

.060800

. .57703

$-.54314$
RE

LAMINAR $.4000 E 04$ $.2000 E 05$ $.1000 E 06$ $.4000 E 06$ $.2000 E 07$ $.1000 E O B$ $.4000 E 08$

$$
\text { VR }
$$

VI

$.081770=.126882$ $.138235-.143449$ $.145804-.144100$ $.154005-.144421$ $.161625 \cdot .144362$ $.171175 ., 143800$ $.181545 \cdot .142566$ $.191185 \cdot .140817$
vS

.100948 .199215 .204997 211128 .216710 .223561 1250833 .257447

\section{$S=6.34961$}

VA

$-.99832$

$\because 80370$

$-.77952$

. .75329

. .72904

. .09870

. .66570

. .03433
RE

UNIFORM 1200E 05 $.4000 E 05$ $.2000 E 06$ $.1000 E 07$ $.4000 E 07$ $.2000 E .08$ $.1000 E 09$
VR

VI

$.233449 \cdot .125380$ $.142470-.143856$ $.149255 \cdot .144284$ $.157748 \cdot 144435$ $.166965=144115$ $.175537 \cdot .143361$ $.186281-.141780$ $.197934-.139234$ vs

VA

$.264968 \quad-.49286$ $.202465-.79023$ $.207593=.76846$ $.213883 \quad .74137$ $.220560 \quad .71207$ $.226640 \quad-.68484$ $.234090=.65057$ $.242000 \quad-.61302$

\section{$S=7.12719$}

VA
VR

V】

UN IFORM

$.104166 \cdot 1.09411$
. $1000 E 05$ $.4000 E 05$ $.2000 E 06$ $.1000 E \cdot 07$ $.4000 E \quad 07$ $.2000 E 0 B$ $11000 E 09$ $.180414 \quad-.88126$ $.166060 \quad-85456$ $.192072=.82583$ .197564 .779924 $.204333 \quad .776596$ $.211548-.72970$ $.218138 \quad . .69574$

$\begin{array}{rlllll}\text { LAMINAR } & .061559 & -.119210 & .194166 & -1.09411 \\ .4000 E & 04 & .114775 & -.139197 & .180414 & . .88126 \\ .2000 E & 05 & .122157 & . .140342 & .166060 & -.85456 \\ .1000 E & 06 & .130214 & -.141194 & .192072 & -.82583 \\ .4000 E & 06 & .137751 & -.141620 & .197564 & -.79924 \\ .2000 E & 07 & .147266 & -.141650 & .20433 & .176596 \\ .1000 E & 08 & .157681 & -.141029 & .211548 & -.72970 \\ .4000 E & 08 & .167437 & -.139817 & .218138 & . .169574\end{array}$

$\begin{array}{llll}.210978 & -.126117 & .245799 & -.53877 \\ .118899 & -.139881 & .183586 & -.80629 \\ .125540 & -.140750 & .188603 & -.84245 \\ .133910 & -.141447 & .194780 & -.81276 \\ .143062 & -.141706 & .201369 & -.78063 \\ .151636 & -.141473 & .207384 & -.75073 \\ .162465 & -.140512 & .214799 & -.71306 \\ .174309 & -.138586 & .222688 & -.07172\end{array}$

VA

.07172 
LAMINAR $.045198 \cdot .108919$ $.4000 E 04 \quad .094810=.131715$ $.2000 E 05 \quad .101942 \cdots .133310$ $.1000 E 06 \quad .109 .784 \cdot .134653$ $.4000 E 06.117174 \cdot .135535$ $.4000 E 06 \quad .117174 .1135535$ $.1000 E 08 \quad .136954-.136102$ $.4000 E 08 \quad .146755 \cdot .135416$

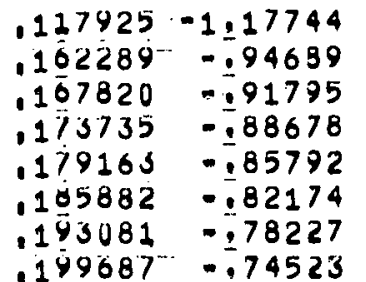
.1000 E. 0. $.4000 E \quad 05$ $.2000 E 06$ $.1000 E 07$ $.4000 E 07$ $.2000 E 08$ .1000E 09

$.191336 \cdot .123449$ $.098788-.132649$ $.105227 \cdot .133924$ $.113402 \cdot .135130$ $.122413 \cdot 0.135938$ $.130919 \cdot .136204$

RE

VR

VI

LAM!NAR $.4000 E 04$ $.2000 E 05$ $.1000 E 06$ $.4000 E .06$ $.2000 E 07$ $.1000 E$ OB $.4000 E 08$

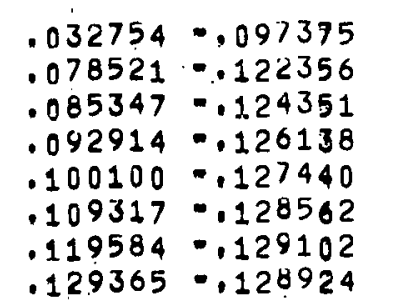

VS

$S=$
$V_{A}$ 8.97970

RE

UNIFORM

$.102737 \cdot 1.24630$ $.145384-1.00024$ $.150822 \quad-.96929$ $.136665 \quad .93572$ $.102055 \quad .90477$ $.168755 \quad-.86612$ $.175976-.82365$ $102639-.78369$ . $1000 E 05$ $.4000 E 05$ $.2000 E 06$ $.1000 E 07$ $.4000 E \quad 07$ $.200 .0 E \quad 08$ $.1000 E 09$
$.141751 \cdot .135848$
$.153704 \cdot .134534$

.204265

\section{RE}

LAN.INAR $.4000 E 04$ $.2000 E 05$ $.2000 E 06$ $.4000 E 06$ $.2000 E 07$ $.1000 E 08$ $.4000 E \quad 08$

\begin{abstract}
VR
\end{abstract}
V.I

$.023892 \cdot .085744$ $.065681-.112290$ $.072157 \cdot .114629$ $.079397 \cdot .116809$ $.086330 . .118489$ $.095299 \cdot .120096$ $105388 \cdot .121166$ $.115089 \cdot .121474$
VS $\quad S=10.07937$

$$
\checkmark A
$$

RE

VR

VI

vs

VA

$.069011-1.29904$ $.130089-1.04153$ $.135449-1.00897$ $.141238 \cdots .97381$ $.146603 \quad-.94113$ $.153313 \quad-.90001$ $.160586-.85492$ $.107336 \quad-.81237$
UNIFORM .161125-.112873 .1000 05 $.069280 . .113636$ $.4000 E 05.075175-.115592$ .2000 06 .082778..117677 $.1000 E 07 \quad .091308-.119458$ $.4000 E 07 \quad .099498 .0120635$ .2U0OE $08 \quad .110115 \cdot .121404$ $.1000 E$ O9 .122065 $\cdot .121258$ vs

VA

$.211647=.59646$ $.148432 \quad-.98290$ $.153286 \quad-.95523$ $.159316 \quad . .92072$ $.165807 \quad-.88327$ $.171799 \quad-.84831$ $.179255=.80409$ $.187276 \quad-.75531$ 
$S=11.31371$

LANINAR , $4000 E \quad 04$ $.2000 E$ OS $.1000 E 06$ $.4000 E 06$ $.2000 E 07$ $.1000 E 08$ $.4000 E 08$

$.017994 \cdot .074898$ $.055783 \cdot .102407$ $.061875-1105030$ $.068748-.107546$ $.075387=.109558$ $.084055=.111602$ $.093906=.113162$ .103474 .113926
$.077030-1.33501$ $.116614-1.07201$ $.127642 \cdot 1.00201$ $.1 \$ 2990 \quad-96809$ $.159713=.92527$ $.147051 \quad . .87812$ $.155902-.83343$

\section{$S=12.69921$}

VA

RE

UN IFURM

$.000914-1.35541$

$.104982-1.09404$

$.110186-1.06005$

$.115866-1.02307$

$.121186-.98845$

$.127915 \quad-.94454$

$.155303-.89594$

$.142249-.84952$

$.1000 E 05$
$.4000 E 05$
$.2000 E 06$
$.1000 E 07$
$.4000 E 07$
$.2000 E 08$
$.1000 E$ OQ
$121902-1.03841$
UNIFORM .1000E 05 $.4000 E 05$ $.2000 E 06$ $.1000 E 07$ $.4000 E 07$ $.2000 E 08$ -1DOOE 09
VR

VI

VS

VA $.2000 E 05$ $.1000 E 06$ $.4000 E 06$ $.2000 E 07$ $.4000 E 08$ $.066650 . .101212$ $.074972=.103640$ $.093922=.106833$

$.149968-.106933$ $.059163 \cdot 103909$ $.064733 .-10613$ $.071979-108575$ $.080187 \cdot .110769$ $.088142=.112346$ $.098557-0.113625$ $.110408-.124023$

.184187 $110572-1.05320$ $.124315 \cdot 1.02310$ $.130267 \quad-.98537$ $.136747 \quad 0.94420$ $.142796-.90553$ $.150413 . .85629$ $.158718-.80150$

RE

VR

VI

$S=14.25438$

VA

RE

VR

V I

vs

VA

LAMINAR $.4000 E 04$ $.2000 E 05$ $.1000 E 06$ $.4000 E 06$ $.2000 E 07$ $.1000 E 08$ $.012048 \cdot .057352$ $.042190=.085158$ $.047459-.088171$ $.053518=.091180$ $.059482 \cdots .093710$ $.067426 \cdot .096469$ $.076658-.098869$

$.038603-1.36375$ $.095036-1.11081$ $.100133-1 \pm 07701$ $.105727=1.04002$ $.110994-1.00521$ $.117697 \quad-.96078$ $.125107 \quad .91126$ $.132120 \quad . .86375$
UNIFURM $.1000 E \quad 05$ $.4000 E 05$ $.2000 E 06$ $11000 E 07$ 4000E 07 $.2000 E 08$ $.1000 E 09$

$\begin{array}{llll}.132784 & -.096493 & .164142 & -.06441 \\ .045100 & -.086871 & .097840 & -1.09193 \\ .049963 & -.089472 & .102477 & -1.06150 \\ .056407 & -0092457 & .104305 & -1.02298 \\ .063859 & -.095313 & .114728 & 0.08049 \\ .071231 & 0.097560 & .120796 & -.09013 \\ .081089 & -.099730 & .128537 & -.08812 \\ .092581 & -.0101122 & .137102 & -.82945\end{array}$


RE

LAMINAR $.4000 E 04$ $.2000 E 05$ $.1000 E 06$ $.4000 E 06$ $.2000 E 07$ $.1000 E 08$ $.4000 E 08$
VR

VI

$.010586 \cdot .050775$ $.037251-.078062$ $.042103 \cdot .081184$ $.047738 \cdots .084354$ $.053340 \cdot .087068$ $.060880 \cdots, 090104$ $.069748 \cdot .092852$ $.078656=.094788$

\begin{tabular}{cc} 
& \multicolumn{1}{c}{$S=16}$. \\
$V S$ & $V A$ \\
021866 & -1.36525 \\
086495 & -1.12555 \\
041452 & -1.09237 \\
096925 & -1.05530 \\
102108 & -1.02114 \\
108743 & -197659 \\
116131 & -.92654 \\
123173 & -187813
\end{tabular}

$S=17.95940$

$\checkmark A$

$.046361-1.36531$ $.079026-1.14079$ $.083814-1.10843$ $.089130-1.07248$ $.094194-1.03815$ $.100718 \quad-.99368$ $.108036 \ldots . .94328$ $.115062 \quad .89412$
RE

UNIFURM . $1000 E 05$ $.4000 E 05$ $.2000 E 06$ $.1000 E 07$ $.1000 E 07$ .2000E: 08 $.1000 E 08$
VR

$.12565 s \cdot .092259$ $.039925-.079831$ $.044425 \cdot .082547$ $.050445 \cdot .085717$ $.057484 \cdot 0.088820$ $.064521=.091336$ $.074043 \cdot .093885$ $.085287 \cdot 095720$

$\begin{array}{cc}V S & V A \\ 155086 & -.03333 \\ 089258 & -1.10704 \\ 093742 & -1.07706 \\ 099450 & -1.03886 \\ 105799 & -.99639 \\ 111827 & -.95577 \\ 119569 & -.90301 \\ 128204 & -.84297\end{array}$

$\begin{array}{ll}.128204 & -.84297\end{array}$

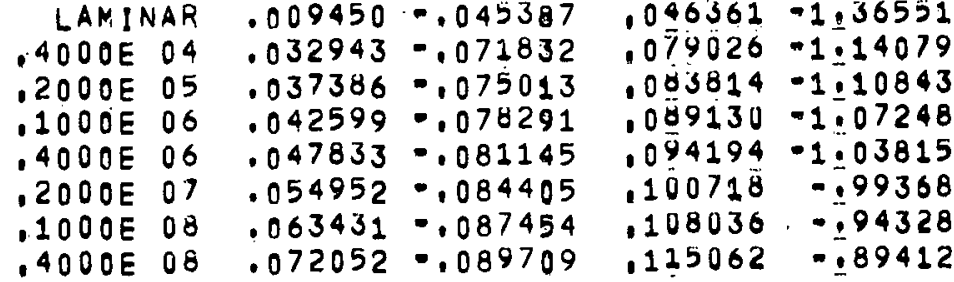

\section{RE}

LAMINAR . $4000 E 04$ $.2000 E 05$ $.1000 E 06$ $.4000 E 06$ $.2000 E 07$ $.1000 E 08$ $.4000 E 08$
VR

V I

$.008383=.040876$ $.029027=.066249$ $.033075 \cdots .069446$ $.037873=.072784$ $.042739=.075736$ $.049431 \cdot .079173$ $.057501 \cdot .082474$ $.065810 . .085015$

\section{vs$$
S=20.15874
$$$$
\text { VA }
$$

RE

$.041 / 2 \%-1.36849$ $.072329-1.15734$ $.076920-1.12630$ $.082049-1.09079$ $.086963-1.05702$ $.043337-1.01257$ $.100540 \quad-.96175$ $.107511=.91204$
UNIFORM $.1000 E .05$ $.4000 E 05$ $.2000 E 06$ $.1000 E \quad 07$ $.4000 E 07$ $.2000 E 08$ $.1000 E .09$
VR

VI

$.118968-.088548$ .035387 .0073629 $.039528 \cdot .076416$ $.045121-.079718$ .051735 .083016 $.058421 \cdot .085757$ $.067575 \cdot .088639$ .078533 .090882
VṢ. VA

$.148304-.63984$ $.081641-1.12277$ $.086034-1.09342$ $.091602-1.05573$ $.097819-1.01349$ $.103760=.07277$ $.111460-.91943$ $.120113 \quad-.85816$
UNIFORM .112533 $. .085163 \quad .141126 \quad-.64782$ $.1000 E \quad 05 \quad .031249-.068050 \quad .074802-1.14031$ $.4000 E 05 \quad .035041=.070869 \quad .079058-1.11159$ $.2000 E \quad 06 \quad .04021 j=.074255 \quad .084444-1.0 .7445$ .1DOOE $07 \quad .046397-.077699 \quad 0090497-1.03248$ $.4000 E 07 \quad .052719 .0080623 \quad .096330 \quad-.99168$ $.2000 E$ 08 $.061482 \cdot 0.083795 \quad .103931 \quad \cdot .93779$ .1000 09 $.072121 \quad 0.086409 \quad .112552 \quad-.07528$ 

- $R E$
VR
V I
vs
$S=22.02742$
$\checkmark A$

LAMINAR $\quad .007301=.036954$ $.4000 E \quad 04 \quad .025408=.061111$ $.2000 E \quad 05 \quad .029082 \quad .064287$ $.1000 E 06.033478=.067646$ $.4000 E$ O6 $.037981=.070658$ $.2000 E \quad 07 \quad .044242 \quad .074225$ $.1000 E \quad 08 \quad .051889=.077736$ $.4000 E 08 \quad .059867 \cdot .080528$

RE

LAMINAR $.4000 E 04$ $.2000 E 05$ $1000 E 06$ $.4000 E 06$ $.2000 E \quad 07$ $.1000 E 08$ $.4000 E 08$
$031069-1.37572$ $.000183-1.17676$ $.070559 \cdot 1.14596$ $.075477-1.11123$ $.080219-1.07757$ $.066410-1.03328$ $.093463 \quad .98220$ $.100345 \quad . .93151$
RE

UNIFORM $1000 E 05$ $.4000 E 05$ $.2000 E 06$ 1 100OE 07 $.4000 E 07$ $.2000 E 08$ $.1000 E$ OS
VR

VI

$.106292 \cdot .081925$ $.027420 \div 062895$ $.030877 \cdot .065713$ $.035638-.069141$ $.041394=.072686$ $.047346 . .075755$ .055699 .079174 $.065989=.082124$ vs

VA

$.134200 \cdot .05665$ $.060613-1.15967$ $.072606-1.13153$ $.077785-1.09487$ $.083646-1.05311$ $.089354-1.01220$ $.096803 \quad . .95772$ $.105351 \quad . .89390$
VR

VI

$.006228 \cdot .033422$ .022087 .056281 $.025406 \cdot .059406$ $.029417 \cdot .062751$ $.033566=.065790$ $.039398 \cdot .069447$ $.046615 \cdot .073124$ $.054242 . .076133$
RE

VR

V I

vs

$S=28.50876$

$\checkmark A$

$S=25$

RE

UNIFORM $1000 E 05$ $.4000 E 05$ $.2000 E \cdot 06$ . IOOOE: 07 $.4000 E 07$ .2000E 08 $.1000 E 09$
VR

VI

$.100271 \cdot .078721$ $.023901-.058033$ $.027039 \cdot .060821$ $.031402-.064254$ $.036736=.067860$ $.042315-.071038$ $.050245 \cdot .074662$ .060161 .077912
Vs
VA
$.127480 \quad-.60557$ $.062762-1.18011$ $.066561 \cdot 1.15246$ $.071517-1.11621$ $.077166-1.07461$ $.082686-1.03356$ $.089994 \quad-.07844$ .098436
. .91325

LAMINAR $.4000 E 04$ $.2000 E \quad 05$ $.1000 E 06$ $.4000 E 06$ $.2000 E \quad 07$ $.1000 E \quad 08$ $.4000 E 08$
$.005227 \cdot .030173$ $.019094 \cdot .051697$ $.022082=.054748$ $.025726 \cdot .058049$ $.029532 \cdot .061085$ $.034941 . .064793$ $.041722 \cdots .068598$ $.048986=.071791$
$030622-1.39924$ $.055111-1.21639$ $.059034-1.18741$ $063495-1.15362$ $.067849 \cdot 1.12046$ $.073614-1.07622$ $.080289 \cdot 1.02435$ $.080911-.97201$
RE

UN IFORM . 10OOE OS $.9000 E 05$ $.2000 E .06$ $1000 E 07$ $.4000 E .07$ $.2000 E 08$ $.1000 E 09$
VR
V I

$.094523-.075508$ $.020724 \cdot .053403$ $.023561-.056139$ $.027542 \cdot .059546$ $.032464 \cdot .063176$ $.037671 \cdot 066429$ $.045167=.070218$ $.054687=.073733$

\begin{tabular}{|c|c|}
\hline Vs & $V A$ \\
\hline $\begin{array}{l}20480 \\
57284 \\
60883 \\
65608 \\
71029 \\
76367 \\
83490\end{array}$ & $\begin{array}{r}-.07403 \\
-1.20062 \\
-1.17342 \\
-1.13756 \\
-1.09611 \\
-1.05493 \\
-.99918 \\
-.93263\end{array}$ \\
\hline
\end{tabular}


LAMINAR $.4000 E 04$ . 2.000E 05 $.1000 E 06$ $.4000 E 06$ $.2000 E 07$ $.1 .000 E 08$ $.4000 E 08$

UN IFORM $.1000 E 05$ $.4000 E .05$ $.2000 E 06$ 1 1000 OT .4000 OT $.2000 E .08$ . $1000 E 09$
$.089089 \cdot .072297$ $.017910-.04900 j$ $.020465-.051667$ $.024083=.055020$ $.028604 \cdot .058642$ $.033442-.061938$ .040500 .065854 $.049605=.069598$
$.114733 \quad 0.68172$ $.052174-1.22038$ $.055573-1.19365$ $.060060-1.15821$ $.065246-1.11697$ $.070390-1.07571$ $.077311-1.01941$ $.085467-.05156$ 


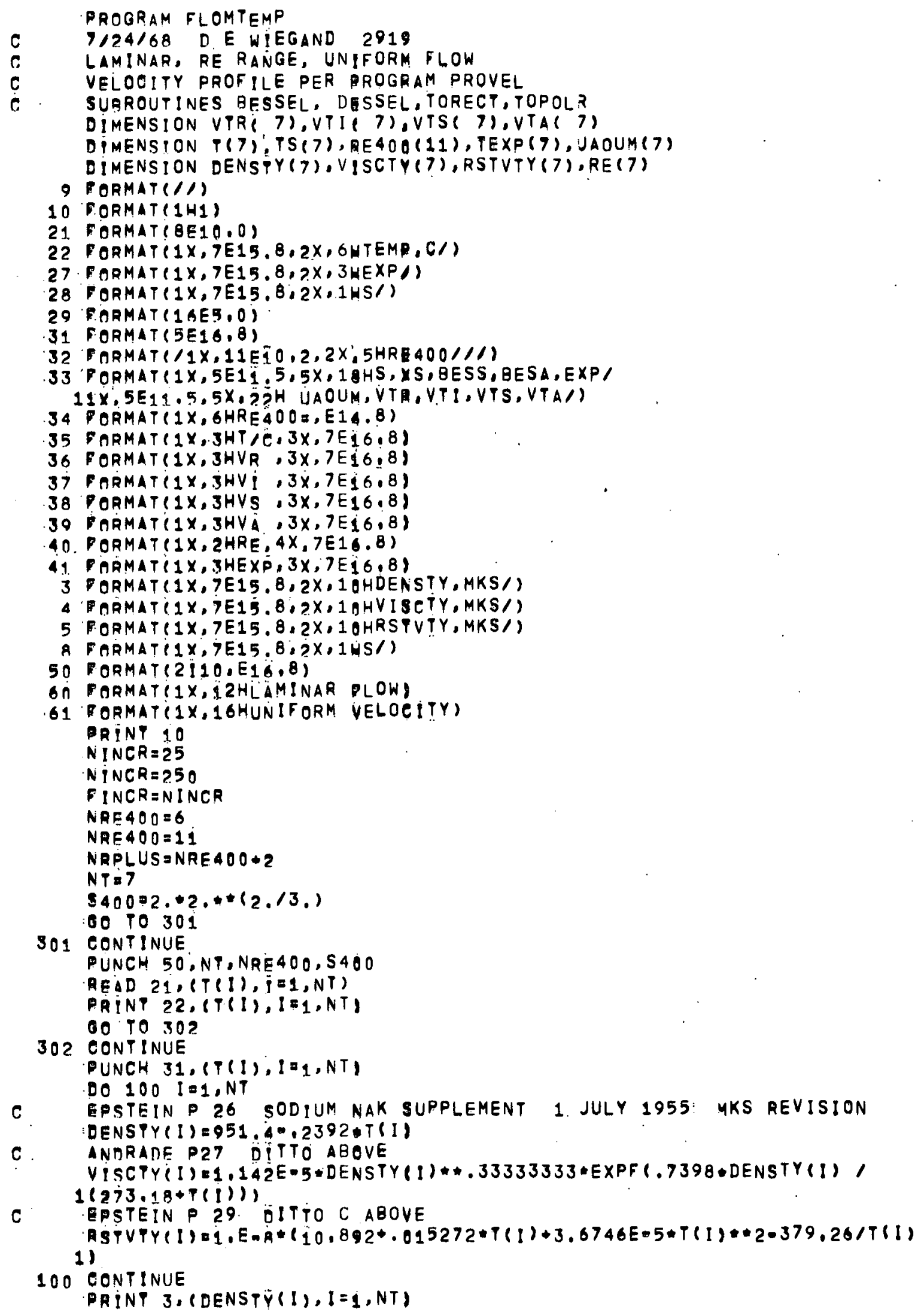


-aint 4, eVISCTy(l), l=i,NT)

ARINT 5 , (RSTVTY $(1), I=1, N T)$

DO $105 \quad I=1, N T$

105 TS(IIES4OO०RSTUTY (4)/RSTVPY(1)

PRINT $8, I T S(I), I=1, N T)$

READ $20,(R E 400(J), J=1, N R E 400)$

ORINP 32, (REAOA (J),J=i, NRE400)

OO TO 303

303 CONTINUE

PUNCH $31,(R E A O A O(J), J=1, N R E 400)$

DRINP 10

NPAGE $=0$

DO $500 \mathrm{~J}=1$, NRPLUS

DO 400 I $1, N T$

if (J.1) 250.252 .250

250 IFiJ-NRPLUS) $251,252,251$

$251 \mathrm{~K}=\mathrm{J}=1$

RE $(!)=R E 40 O(K)$ DENSTY $(1) / D E N S T Y(4)+V I S C T Y(4) / V I S C T Y Y(!)$

UAOUM(I) $=.655+.035 * .43429448 *$ LOGF (RE (I))

TEXP(1) FUAOUMP I I)/(1,-UAOUM( 1$))$

252 :CONTINUE

$V T R(1)=0$.

$V P(P(t)=0$.

STS $x(1)$

$X S=S O R T F(2, * S)$

CAILL BESSEL (XS,BESR,BES!)

CALL TOPOLR(BESR,BESI',BESS, BESA)

DELTAASS/FINCR

$A(-.5) \oplus D E L T A A$

DO 90 O M I, NINCR

$A \cap A+D E L T A A$

$P X=S Q R T F(2 . * A)$

CALL DESSEL (PX,PDBESR',PDBES!)

- UUNCR $=2 .+P D B E S R * P D B E S I$

FUNC I=PDBES I +2 $=P D B E S R * 2$

$\operatorname{Cos} \approx P X+2 / 2,15$

IF (J.1) $253,254,253$

253 TF(JONRPLUS) $255,256,255$

254 UTOUA $=2, *(1,-A O S)$

OO $T 0257$

255 UTOUA $=(1,-A O S+T E X P(I) / U \Delta O U M(I)$

$00 \quad 10257$

256 UTOUA $=1$.

257 CONTINUE

VTR (I) =VTR(1) +FUNCR UYOUA

VTI (I) $=V T I(1)$ OFUNEI U OUA

90 CONTINUE

CORR \#F INCR •BESS**2

CORA $B E S A+2$.

CALL TOPOLR(VTR(I),VTI(I),VTS(I),VTA(I))

VTS $(1)=V T S(I) / C O R R$

$V T A(1)=V T A(I)-C O R A$

OALL TORECT(VTR(I),VTI(I),VTS(I),VTAPI))

EALL TOPOLR(VTR(I),VTI(I),VTS(I),VTA(I))

400 CONTINUE

(F)(J-1) $258,259,258$

258 IF(JONRPLUS) $200,261,260$

259 RIN 60

PRINT 35, $(T(1), I=1, N T)$

GO TO 26 ?

260 BRINP 34, RE $400(K)$

PRINT 35, (T (I), I E , NT) 
PRINT 40, (RE (I),I=1,NP)

DQNT 41, (TEXPi(I), Ia1,NT)

00 TO 262

261 PRINT 61

PAINT $35,(T(I), I=1, N T)$

262. CONTINUE

PAINT 36, (VTRII), I=1,NT)

BO 10306

306 CONTINUE

PUNCH31, (VTRP I :, I I1,NP)

DRINT $37,(V T I(I), i=1, N T)$

00 TO 307

.307 CONTINUE

RUNCH31, (VTI (I), I:1,NY)

ARINT 38, (VTS $(i), i=1, N T$ )

PAiNT 39, (VTA $(i), i=1, N T)$

PAINT 9

NPAGE $=N P \triangle G E+1$

IF (NPAGE-4) $236: 236,237$

$237: P R I N T 10$

$N P \triangle G E=0$

236 CONTINUE

SOO CONTINUE

END

100.

200.300.

400.

500

600.

700

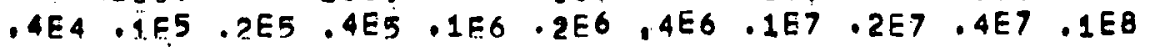




\section{APPENDIX D}

Program PIPELOSS

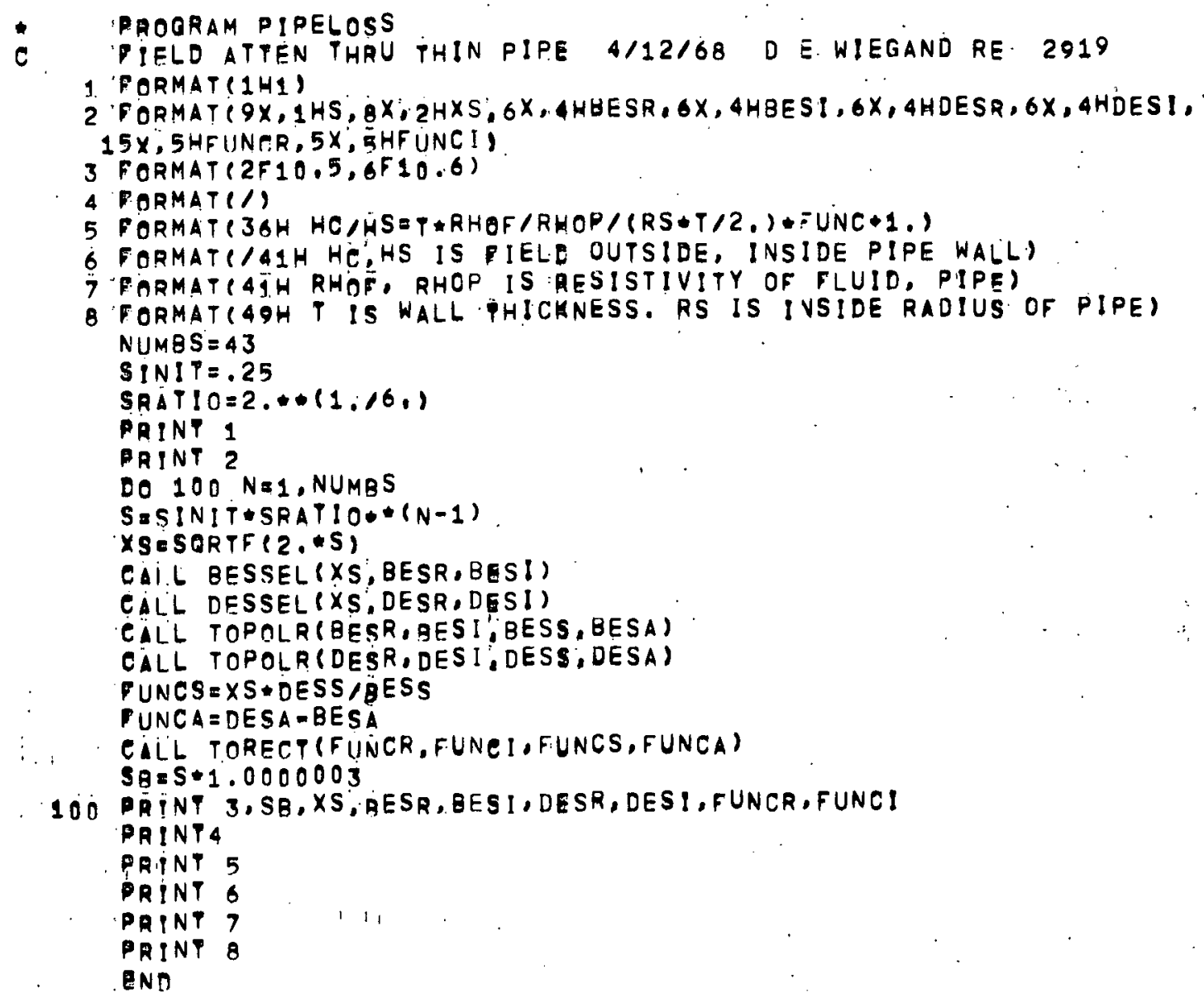




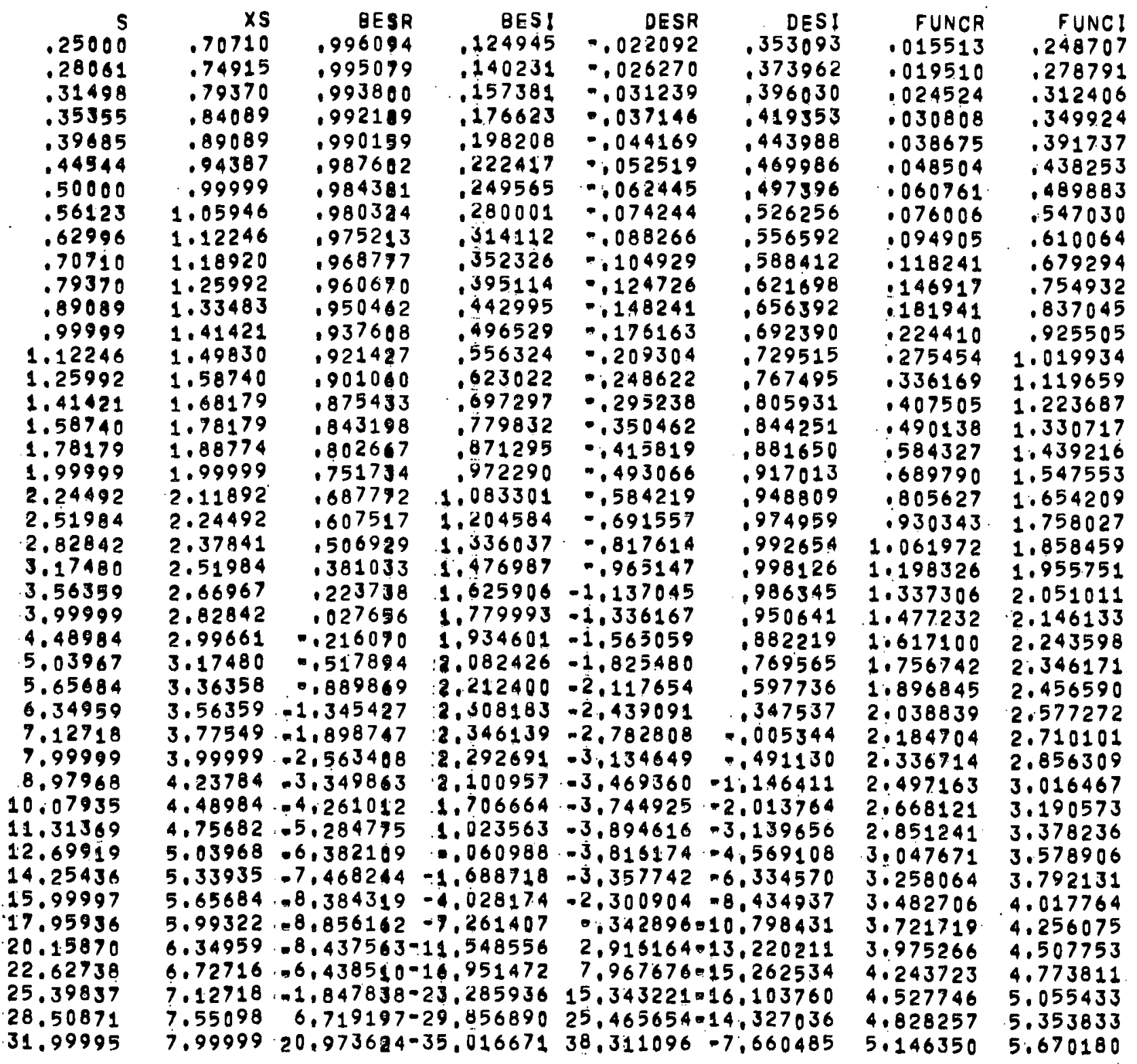

HCAHSAP RHOF/RHOP/(RS\$T/2, ) \&UNE \& 1 ,

HCIHS IS FIELD OUTSIOE, INSIDE PIPE WALL RHOF: RIOP IS RESISTIVITY OP FLUID, PIPE P. IS WALLi THICKNESS. RS IS INSIBDE RADIUS OF PIPE 


\section{APPENDIX E}

\section{Subroutines}

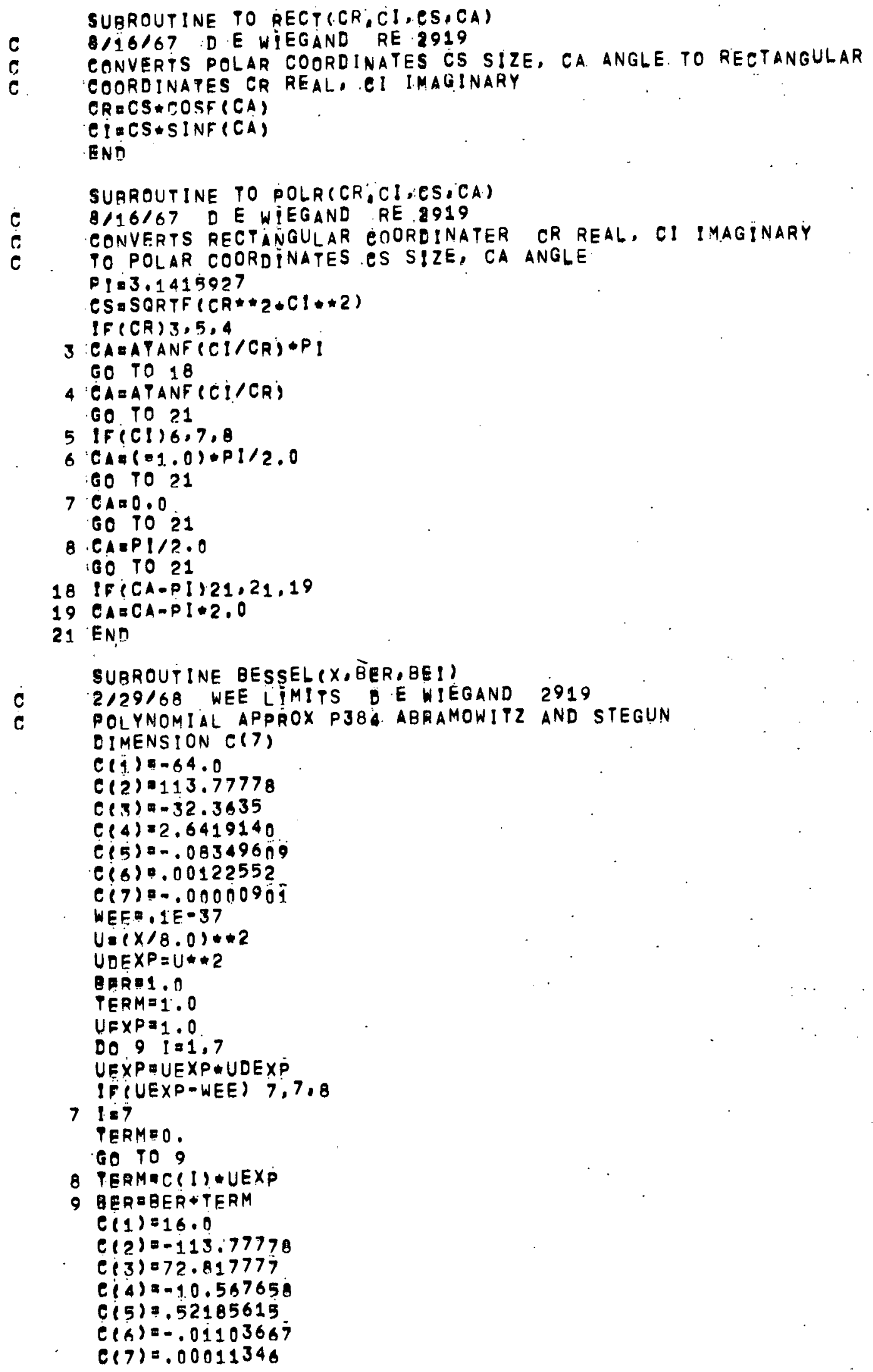




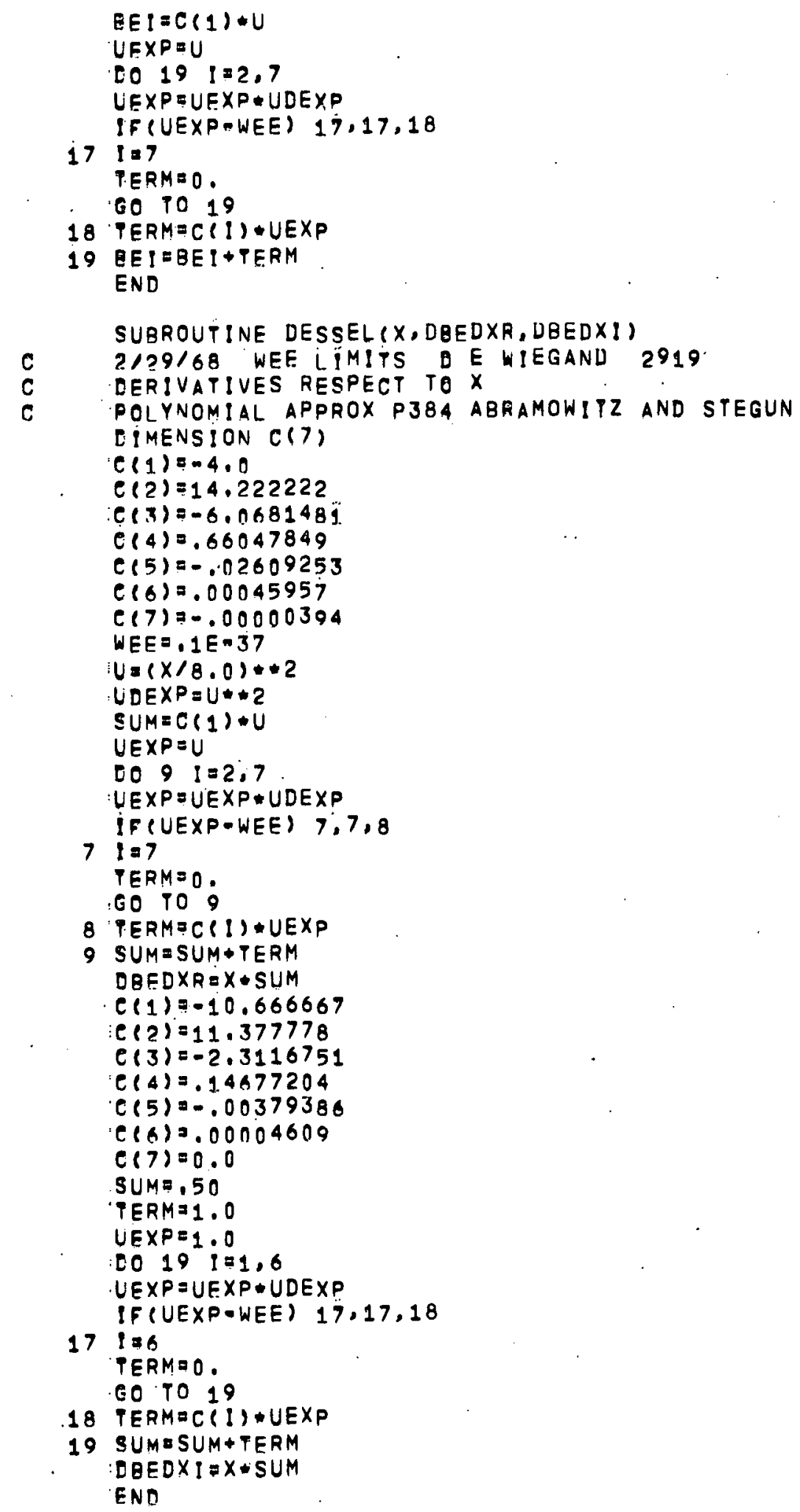


SUBROUTINE BORDER (PEN, DRUM, NPEN,NDRUM)

FNPENPEN

FND $=$ NDRUM

$C A=P E N / F N P$

$D B=D R U M / F N D$

$A=P L O T F(1,0,1,0.1)$

PEPLOTF $(0,0,0.0 .2)$

F.PLOTF $(0.0 .0 .0 .3)$

00512 Ia1. NPEN

$P i=1$

$A=F I+D A$

FaPLOTF $(A .0 .0 .4)$

$F=P L O T F(A, 0,1,4)$

512 aPLOTF $(A, 0,0,4)$

EO $513 \quad l=1$, NDRUM

$F \mathrm{I}=\mathrm{l}$

$B=F ! * D B$

$P E P L O T F(P E N, B .4)$

$P E R=P E N-.1$

$P \cong P L O T F(P E R, B, 4)$

513 PIPLOTF(PEN, B,4)

CO 514 I $=1, N P E N$

PI:I

$\triangle \triangle P E N-F I+D A$

A.PLOTF(A,DRUM, 4$)$

QRUR $=$ DRUM -1

APLOTF (A, DRUR, 4$)$

514 F.P.LOTF (A,DRUM, 4)

CO $515 \quad l=1$. NDRUM

$F i=!$

$Q=D R U M-F I \oplus D B$

$F \cong \operatorname{PLOTF}(0,0,8,4)$

$F=P L O T F(0,1,8,4)$

515 PaPLOTF $(0,0,8,4)$

$P=P L O T F(0.0,0,0,3)$

END

SURROUTINE MOVEUP (HOWFAR)

FIPLOTF $(1,1.11)$

a PLOTF $(0,0,0,2)$

PaPLOTF(O.. HOWFAR, 3 )

END

$\dot{\mathrm{c}}$

SUBROUTINE BORLOG(PEN, DRUM, NPEN,NDRUM)

E E WIEGAND RE DIV 2919 9/14/67

FNP $=$ NPEN

TNDENDRUM

$D R U M R=D R U M-.1$

PENR = PEN-.1 1

PAPLOTF $(1,1,1,1)$

FEPLOTF $(.0,0,0,2)$

P.PLOTF $(.0,0,0,3)$

(F (NPEN) 40.40 .5

5 . $39 \quad i=1,2$

DO $29 N=1, N P E N$

$F N=N$

DO $19 M=1,10$

F $M=M$

$X=.43429448+P E N / F N P-L Q G F(P M)+P E N+(F N-1.0) / F N P$

$P=P \operatorname{LOTF}(X, .0,3)$

$P=P L O T F(x, .1,4)$

19 MPLOTF $(X, 0.4)$ 
29 CONTINUE

IF(INI) $38,38,39$

38 P=PLOTF $(, 0, D R U M R, 3)$

FaPLOTF $(.0,00,2)$

39 A APLOTF $(0,0,0,3)$

P. PLOTF $(.0$. DRUMR, 2)

$P=P L O T F(.0,0,3)$

40 CONTINUE

IF(NDRUM) 90.90 .45

$450079 \quad 1=1,2$

DO $69 \mathrm{~N}=1$, NDRUM

$F \mathrm{~N}=\mathrm{N}$

CO $59 M=1,10$

$F M=M$

$Y=.43429448 * D R U M / F N D * L O G F(F M)+D R U M *(F N-1: 0) / F N D$

$P=P L O T F(-0, Y, 3\}$

PaPLOTF $(, 1, Y, 4)$

59 P. .PLO.TF $(, 0, Y, 4)$

O CONTINUE

$\{[(!=1) 78,78,79$

$78 \mathrm{PaPLOTF}$ (PENR, $, 0,3$ )

$F=P L O T F(, 0,00,2)$

$79 P=P L O T F(.0,00,3)$

PaPLOTF (PENR,.0,2)

P.PLOTF $(.0,00,3)$

90 CONTINUE

END 
I gratefully acknowledge the assistance of Charles. W. Michels of. the Reactor Engineering Division in the preparation of the computer programs, and the helpful comments of other members of Argonne National Laboratory who reviewed the manuscript. 


\section{REFERENCES}

1. Lehde, H., and Lang, W., U.S. Patent Number 2,435,043 (Jan. 27, 1948).

2. London Conference on Fast Breeder Reactors, British Nuclear Society; May 17-19, 1966, Control and Instrumentation of Prototype Fast Reactor.

3. Shercliffe, J. A., Theory of Electromagnetic Flow Measurement, Cambridge University Press (1962).

4. Wiegand, D. E., Summary of an Analysis of the Eddy-Current Flowmeter, 14th Nuclear Science Symposium, IEEE, Los Angeles (Oct 1967)。

5. Wiegand, D。 E。, and Michels, C。W., Performance Tests on an Eddy-Current Flowmeter, 15th Nuclear Science Symposium, IEEE, Montreal, October 1968。

6. Popper, G。 F。 Wiegand, D. E。, and Glass, M。 Co, Summary Review of Flowmeters Suitabie for Measuring Sodium Filow at Temperculures up to $1200^{\circ} \mathrm{F}$ in the Fast Flux Test Facility (FFTE), ANL-7340 (Dec 1967)。

7. Abramowitz, M., and Stegun, I. A., Handbook of Mathematical Functions, Dover Publications, Inc。, New York (1964).

8. Brown, G. V., and Flax, L., Superposition Calculation of Thick Solenoid Fields from Semi-Infinite Solenoid Tables, Technical Note NASA-TN-D2494 (Sept 1964)。

9. Knudsen, J. G., and Katz, D. L., Fluid Dynamics and Heat Transfer, McGraw Hill, New York (1958)。

10. Liquid Metals Handbook: Sodium NaK Suppiement, TID-5277 (July, 1955). 